\title{
Study on Nonlinear Dynamic Behavior and Stability of Aviation Pressure Servo Valve-controlled Cylinder System
}

\author{
Yan-he Song \\ Yanshan University

\section{Yuan Wang \\ Yanshan University \\ Jun-xiao Zhang \\ Yanshan University \\ Bin Yu \\ Yanshan University \\ Qi-wei Zhang \\ Yanshan University \\ Xiang-dong Kong \\ Yanshan University}

Kaixian Ba ( $\sim$ bkx@ysu.edu.cn )

Yanshan University https://orcid.org/0000-0002-0434-5351

\section{Research Article}

Keywords: Large aircraft, Pressure servo valve-controlled cylinder system (PSVCS), Nonlinear self-excited oscillations, Stability , Dynamics

Posted Date: July 20th, 2021

DOI: https://doi.org/10.21203/rs.3.rs-666429/v1

License: (c) (1) This work is licensed under a Creative Commons Attribution 4.0 International License.

Read Full License

Version of Record: A version of this preprint was published at Nonlinear Dynamics on March 30th, 2022. See the published version at https://doi.org/10.1007/s11071-022-07366-x. 


\title{
Study on Nonlinear Dynamic Behavior and Stability of Aviation Pressure Servo Valve-controlled Cylinder System
}

Yan-he Song ${ }^{1}$, Kai-xian $\mathrm{Ba}^{1,2^{*}}$, Yuan Wang ${ }^{1}$, Jun-xiao Zhang ${ }^{1}$, Bin $\mathrm{Yu}^{1,2}$, Qi-wei Zhang $^{1}$, and Xiang-dong Kong ${ }^{1,2 *}$

${ }^{1}$ School of Mechanical Engineering, Yanshan University, Qinhuangdao 066004, China

${ }^{2}$ Hebei Provincial Key Laboratory of Heavy Machinery Fluid Power Transmission and Control, Qinhuangdao, China

Corresponding author: Kai-xian Ba (e-mail: bkx@ysu.edu.cn), Xiang-dong Kong (e-mail: xdkong@ysu.edu.cn)

\begin{abstract}
In this paper, for the phenomenon of self-excited oscillation caused by nonlinear factors in a large aircraft wheel brake control system, the nonlinear dynamic behavior of the pressure servo valve-controlled cylinder system (PSVCS) is studied, and the influence law of the key parameters on the nonlinear self-excitation behavior is obtained. On this basis, the stability of the PSVCS is analyzed both in time domain and frequency domain, and it is proved in principle that the PSVCS is a stable self-closed loop control system. Firstly, the nonlinear dynamics model of the PSVCS is established in this paper. Secondly, using the method of phase plane analysis, the nonlinear dynamic behavior of the PSVCS and the influence law of key parameters on the system are studied. Thirdly, the nonlinear system of the PSVCS is transformed into a segmented local linear system, and the stability of the prestage and the power stage are analyzed and studied respectively. Finally, through a performance test platform, which is used to simulate the load of PSVCS, the theoretical analysis results of this paper are verified experimentally under a variety of working conditions. The final experimental results show that both the nonlinear dynamic model established in this paper and the influence law of the key parameters obtained by the phase plane analysis on the nonlinear self-excited oscillation behavior are correct, and the relevant conclusions can provide a reference for the design of the braking system control system.
\end{abstract}

Keywords: Large aircraft; Pressure servo valve-controlled cylinder system (PSVCS); Nonlinear self-excited oscillations; Stability ; Dynamics

\section{Introduction}

Large aircraft is the crown of modern industry and an important embodiment of a country's comprehensive national strength, and it is an important guarantee for national security and an important pillar for national economic development ${ }^{[1,2]}$. In the flight control system of large aircraft, wheel brake control system is one of the subsystems with independent functions, which plays the role of bearing the weight and load of aircraft and providing braking function in take-off and landing ${ }^{[3,4]}$. In April 2021, during the process of collection major scientific issues and engineering technical problems launched by China Association for Science and Technology, the Chinese Society of Aeronautics listed "How to break through the technical problems of high reliability of aviation brake pressure servo valve in extreme environment" as one of them. So the relevant research on aviation pressure servo valve has become a 
hot topic.

Nonlinear self-excited oscillation is a common phenomenon in hydraulic system, and in most cases it will bring significant negative effects to the system, such as vibration noise, fatigue damage and so on. So many scholars in this field have devoted a great deal of energy to carry out the following related research work.

Aiming at the problem of self-excited oscillation during the operation of hydraulic check valve, Grinis et al. determined that the inducement of self-excited oscillation of hydraulic check valve was the fluid-solid coupling between the spool and the fluid during the rotation of the ball valve ${ }^{[5]}$. Han et al. analyzed the self-excited oscillation behavior of the impeller blade of a ship's water-jet propulsion shaft under the action of fluid-induced thrust load ${ }^{[6]}$. Wei et al. used Hopf bifurcating theorem and center manifold theorem to analyze multiple limit-cycle self-excited vibration of the vehicle caused by front wheel shimmy ${ }^{[7]}$. Li et al. analyzed the Hopf bifurcation phenomenon of aircraft hydraulic rudder surface actuator system under external load ${ }^{[8]}$. Motallebia et al. carried out dynamic stability analysis and modeling research of hydraulic lathe against self-excited vibration during cutting process ${ }^{[9]}$.

In terms of nonlinear system stability analysis, common methods include root locus method, Lyapunov's stability theory ${ }^{[10]}$, descriptive function method ${ }^{[11]}$, Popov superstability ${ }^{[12]}$, phase plane method ${ }^{[13]}$, etc. Ronilson et al. used the root locus method and the descriptive function method to analyze the stability of cubic polynomial nonlinear Chua circuits ${ }^{[14]}$. Islam et al. applied the Lyapunov stability theory to the nonlinear controller of ship heading and analyzed the global asymptotic stability of the system ${ }^{[15]}$. Using Lyapunov stability theory and Lipschitz condition in chaotic systems, Zare et al. proposed a robust adaptive control strategy to synchronize a class of uncertain chaotic systems with unknown time delays ${ }^{[16]}$.

At the same time, the research on the stability of servo control system mainly focuses on the high frequency oscillation problem of electro-hydraulic servo valve, namely the noise problem. Zhang et al. thought that the performance of the electro-hydraulic servo valve is greatly affected by the flow field characteristics of the pilot stage, and studied the unsteady cavitation in flapper-nozzle pilot valve numerically and experimentally ${ }^{[17]}$. Glaun et al. thoroughly analyzed the excitation effect of the fluid inside the servo valve on the valve, and realized the vibration and noise reduction of the servo valve ${ }^{[18]}$. Liu et al. proposed an adaptive power stage control (APLC) algorithm in frequency domain to solve the problem of parameter variation in EHST system application in power stage control ${ }^{[19]}$. Wang et al. evaluated the mass of theoretical and experimental vibration waveforms under different supply pressures and vibration frequencies based on the total harmonic distortion (THD) theory ${ }^{[20]}$. Liu et al. proposed a new high frequency electro-hydraulic vibration method independently controlled by two valves, which realized the independent adjustment and control of the frequency, magnitude and offset of the vibration waveform under the condition of high frequency vibration ${ }^{[21]}$.

Through mathematical modeling and experimental research, the self-excited oscillation phenomenon in a large number of hydraulic systems is analyzed, and some effective vibration suppression measures are proposed. However, for the self-excited 
oscillation mechanism of the brake pressure servo valve-actuator system, there is a lack of relevant research work.

Brake pressure servo valve-actuator system is a typical force closed loop hydraulic control system and there are many nonlinear factors in this system. If the nonlinear factors include essential nonlinear links (that cannot be linearized), it is highly likely to cause the nonlinear self-excited oscillation behavior of the system. The first contribution of this paper is finding out the influence law of key parameters on the nonlinear self-excited oscillation behavior.

In addition, the PSVCS is also a servo control system with pressure closed loop. Although its vibration is the self-excited oscillation of the nonlinear system, the stability of the system will also have a certain influence on the vibration behavior. Therefore, the analysis of the stability of the PSVCS is the second contribution of this paper.

Based on the above situation, the structures of the paper are organized as follows:

In Section 2, the nonlinear dynamics model of PSVCS is derived. In Section 3, the nonlinear self-excited oscillation behavior of the PSVCS is analyzed firstly. Then the effect of oil return volume on the nonlinear self-excited oscillation of the PSVCS is studied by using the method of phase plane analysis. In Section 4 , the PSVCS is decomposed locally, and the stability of the prestage and the power stage are analyzed respectively. In Section 5, the correctness of the PSVCS dynamic model established in this paper and the influence law of the proposed oil return volume on the nonlinear self-excited oscillation of the PSVCS is verified experimentally by using the load simulation performance test platform under different working conditions.

\section{Dynamic modeling of PSVCS}

\subsection{System introduction}

The hydraulic schematic diagram of the PSVCS is shown in Fig. 1. The whole system is mainly composed of four parts, namely: the hydraulic oil source, the pressure servo valve, the servo hydraulic cylinder, the oil return channel composed of the oil return pipe and the oil return relief valve. The oil return relief valve is used to adjust the back pressure of the system.

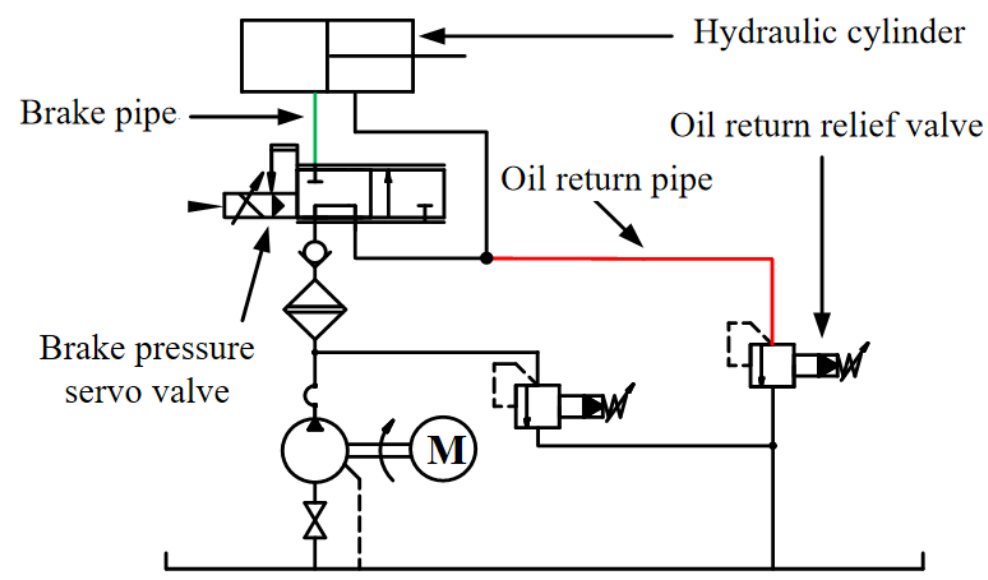

Fig. 1. The hydraulic schematic diagram of the PSVCS 
The pressure servo valve in Fig. 1 is a jet pipe type three-stage pressure servo valve, which controls the output pressure through pressure feedback. The structure schematic diagram of the pressure servo valve is shown in Fig. 2.

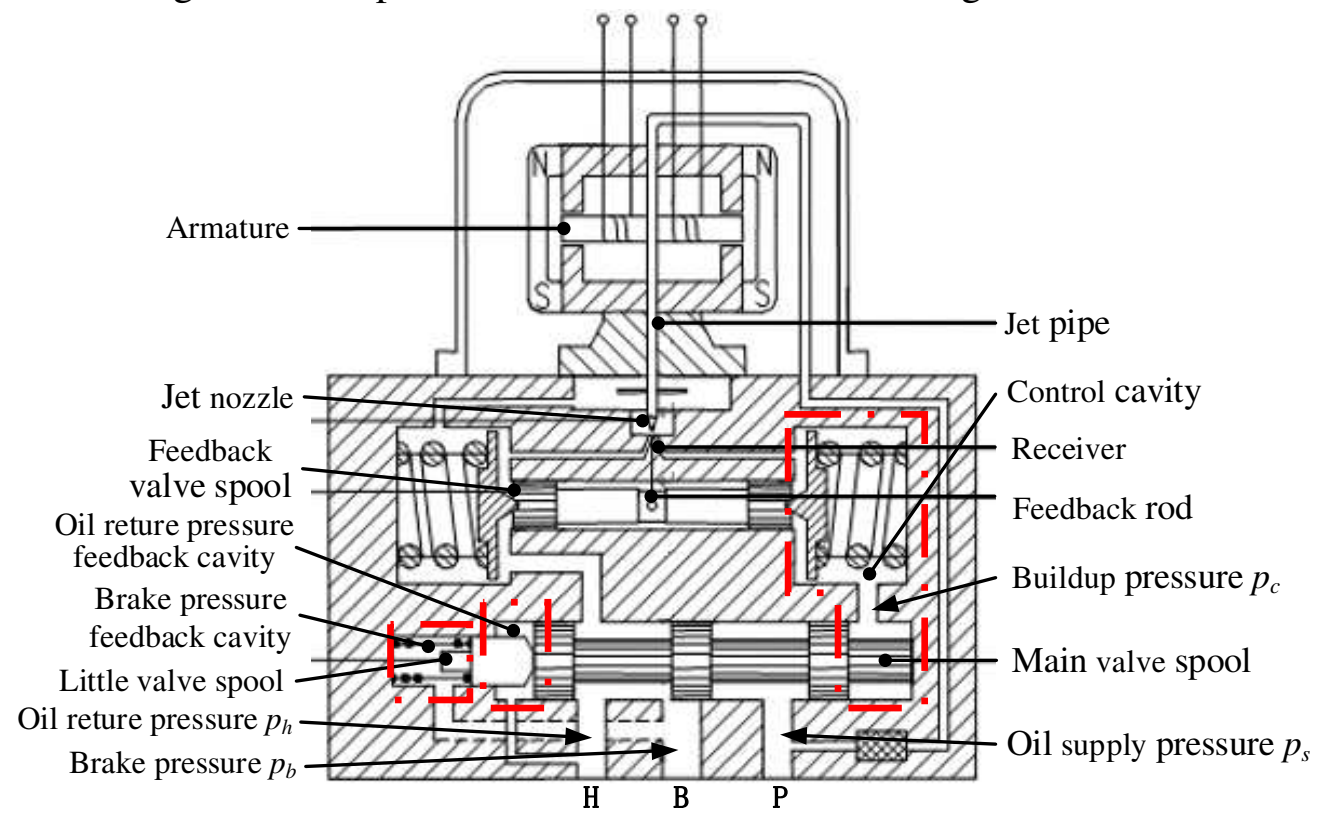

Fig. 2. The structure schematic diagram of the pressure servo valve

In Fig. 2, part of the high-pressure oil entering through port $\mathrm{P}$ reaches the jet pipe through the oil path on the right side of the valve, forming a high-speed jet at the jet nozzle. Port B is connected with the servo hydraulic cylinder and the feedback cavity of working pressure on the left side of the main valve spool simultaneously. Port $\mathrm{H}$ is connected with the oil return channel, which is connected with the pressure cavity of oil return on the left side of the main spool. The specific working principle is as follows:

When there is no current signal, the armature component doesn't turn. Because the jet pipe of valve is facing the left receiving hole of the receiver at the initial position, the jet flow of the jet pipe flows into port $\mathrm{H}$ at this time. The pressure on both sides of the feedback valve spool is the oil return pressure, and the feedback valve spool is stable in the middle position under the action of the spring force on both sides. The main valve spool is pushed to the right under the action of the left return spring, and the port B is connected with the port $\mathrm{H}$, the servo valve doesn't output working pressure.

When there is a current signal, the armature component begins to turn, and drives the jet pipe deflect to the right, which prompts the jet flow through the right hole of the receiver into the control cavity. Then pressure is built up in the cavity, and it push the feedback valve spool and main valve spool to move to the left. At this point, port $\mathrm{B}$ is connected with port $\mathrm{P}$, but disconnected from port $\mathrm{H}$, high pressure oil flows into the rodless cavity of the servo hydraulic cylinder through port $\mathrm{B}$, forming working pressure. Meanwhile, the working pressure will be fed back to the pressure feedback cavity through the inner flow channel of the valve body, forming a negative feedback of working pressure. At this time, the main valve spool will form a dynamic force balance under the joint action of the reset spring force, working pressure, oil return pressure and right cavity pressure. 


\subsection{Mathematical modeling}

\subsubsection{Dynamics model of pressure servo valve}

The spring tube-feedback rod of pressure servo valve will generate feedback force on the feedback valve spool, so the force balance equation is shown as follows:

$$
T_{d}=K_{t} \Delta i+K_{m} \psi==J_{a} \frac{\mathrm{d}^{2} \psi}{\mathrm{d} t^{2}}+B_{a} \frac{\mathrm{d} \psi}{\mathrm{d} t}+K_{a} \psi+K_{f g}\left(r \psi+x_{c}\right)(r+b)
$$

Where, $T_{d}$ is the electromagnetic torque $(\mathrm{N} \cdot \mathrm{m}) ; \psi$ is the flip angle of armature or jet pipe (rad); $K_{m}$ is the magnetic torque spring stiffness $(\mathrm{N} \cdot \mathrm{m} / \mathrm{rad}) ; \Delta i$ is the control current (A); $K_{t}$ is the electromagnetic torque coefficient $(\mathrm{N} \cdot \mathrm{m} / \mathrm{A}) ; J_{a}$ is the rotational inertia of armature component $\left(\mathrm{kg} \cdot \mathrm{m}^{2}\right) ; K_{a}$ is the stiffness of spring tube $(\mathrm{N} \cdot \mathrm{m} / \mathrm{rad}) ; B_{a}$ is the damping coefficient of armature component $(\mathrm{N} \cdot \mathrm{m} / \mathrm{rad} / \mathrm{s}) ; K_{f g}$ is the stiffness of feedback rod $(\mathrm{N} / \mathrm{m}) ; r$ is the distance from the center of rotation of the feedback rod to the nozzle $(\mathrm{m}), r \approx r \cdot \sin (\psi) ; x_{c}$ is the initial offset of the second stage valve spool $(\mathrm{m}) ; b$ is the distance between the nozzle and the connection point of the feedback rod and the valve spool (m).

The relative position relationship between the jet nozzle and the receiving holes and the equivalent coincidence area are shown in Fig. 3 and Fig. 4.

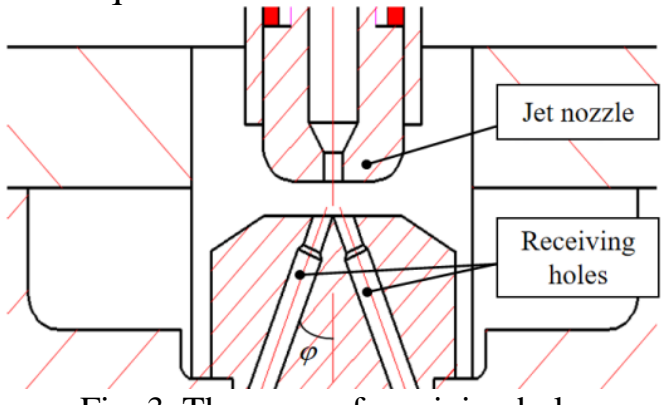

Fig. 3. The areas of receiving holes

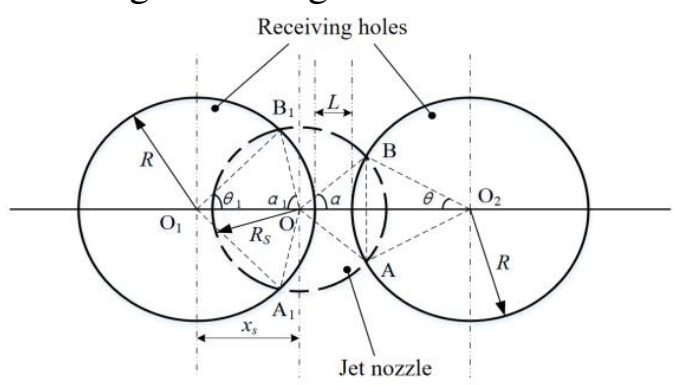

Fig.1. The jet nozzle and the receiving holes

According to the geometric relationship in Fig. 3, the areas of the left and right receiving holes (namely $A_{L}$ and $A_{R}$ ) are as follows:

$$
\begin{gathered}
A_{L}=\left\{\begin{array}{lc}
\pi R_{s}^{2}, & 0 \leq x_{s} \leq R-R_{s} \\
R_{s}^{2} \alpha_{1}+R^{2} \theta_{1}-R_{s}^{2} \cos \alpha_{1} \sin \alpha_{1}-R^{2} \cos \theta_{1} \sin \theta_{1}, & R-R_{s}<x_{s}<R+R_{s}, \text { 且 } \alpha_{1} \geq \frac{\pi}{2} \\
R_{s}^{2} \alpha_{1}+R^{2} \theta_{1}-x_{s} R_{s} \sin \alpha_{1}, & R-R_{s}<x_{s}<R+R_{s}, \text { 且 } \alpha_{1}<\frac{\pi}{2} \\
0, & 0 \leq x_{s} \leq L+R-R_{s}
\end{array}\right. \\
A_{R}= \begin{cases}0, & L+R-R_{s}<x_{s}<L+R+R_{s}, \text { 且 } \alpha<\frac{\pi}{2} \\
R_{s}^{2} \alpha+R^{2} \theta-d R_{s} \operatorname{gsin} \alpha, & L+R-R_{s}<x_{s}<L+R+R_{s}, \text { 且 } \alpha \geq \frac{\pi}{2} \\
R_{s}^{2} \alpha+R^{2} \theta-R_{s}^{2} \cos \alpha \sin \alpha-R^{2} \cos \theta \sin \theta, & L+R+R_{s} \leq x_{s} \leq L+2 R \\
\pi R_{s}^{2}, & \end{cases}
\end{gathered}
$$

Where, $x_{j}$ is the displacement of jet nozzle; $R$ is the radius of receiving hole; $R_{s}$ is the radius of jet nozzle; $L$ is the distance between the edge of the receiving hole and the center line. The remaining parameters are shown in Fig. 4.

As shown in Fig. 3, there is an angle $\varphi$ between the axis of the receiving hole and the vertical direction. Therefore, the actual receiving area is as follows: 


$$
A_{L}^{\prime}=\frac{A_{L}}{\cos \varphi}, A_{R}^{\prime}=\frac{A_{R}}{\cos \varphi}
$$

Part of the high-speed jet formed at the jet nozzle enters the right receiving hole to form the buildup pressure, acting on the feedback valve spool and the power valve spool. Its structure is shown in Fig. 5.

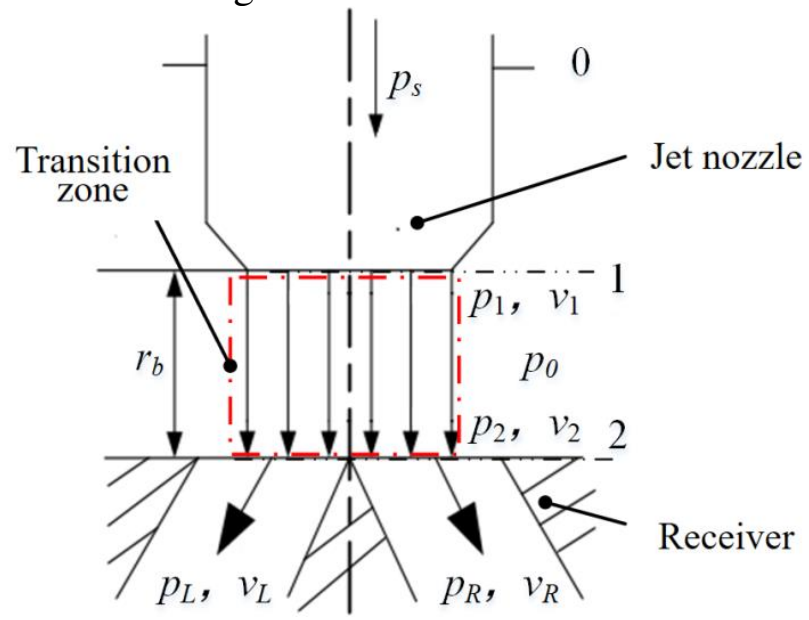

Fig. 5. The structure diagram of jet nozzle-receiver follows:

The Bernoulli equation between cross-sections 1 and cross-sections 2 is as

$$
p_{0}+\frac{1}{2} \rho v_{1}^{2}+\rho g\left(h+r_{b}+\frac{l}{2} \psi^{2}\right)=p_{0}+\frac{1}{2} \rho v_{2}^{2}+\rho g h
$$

Where, $r_{b}$ is the distance between the jet nozzle and the receiver $(\mathrm{m}) ; \quad h$ is the height of water head of the cross-sections $2(\mathrm{~m}) ; l$ is the length of jet nozzle $(\mathrm{m})$.

According to Equation (5), the flow velocity through cross-section 2 can be obtained as follows:

$$
v_{2}=\sqrt{C_{d s}^{2} \frac{2}{\rho}\left(p_{s}-p_{0}\right)+2 g\left(r_{b}+\frac{l}{2} \psi^{2}\right)}
$$

Part of the jet flow through cross-section 2 enters the control cavity in Fig. 1 through the right receiving hole to form the buildup pressure $p_{c}$, and the following equation can be obtained:

$$
p_{0}+\frac{1}{2} \rho v_{2}^{2}\left(\frac{A_{R}^{\prime}}{A_{s}}\right) \xi=p_{c}
$$

Where, $\xi$ is the inlet loss coefficient.

According to Equations (6) and (7), an equation can be obtained as follows.

$$
p_{0}+\frac{1}{2} \rho\left[C_{d s}^{2} \frac{2}{\rho}\left(p_{s}-p_{0}\right)+2 g\left(r_{b}+\frac{l}{2} \psi^{2}\right)\right]\left(\frac{A_{R}^{\prime}}{A_{s}}\right) \xi=p_{c}
$$

According to the flow conservation law, the pressure in the transition zone is as follows:

$$
p_{0}=\frac{A_{s}^{2} C_{d s}{ }^{2} p_{s}+A_{t}^{2} C_{h}^{2} p_{h}}{A_{s}^{2} C_{d s}{ }^{2}+A_{t}^{2} C_{h}^{2}}
$$

Where, $A_{t}$ is the total oil return area of the receiver; $C_{h}$ is the throttle coefficient.

Substituting Equation (9) into Equation (8), the buildup pressure can be obtained as follows: 


$$
\begin{aligned}
p_{c}= & \frac{A_{s}^{2} C_{d s}{ }^{2} p_{s}+A_{t}^{2} C_{h}^{2} p_{h}}{A_{s}^{2} C_{d s}{ }^{2}+A_{t}^{2} C_{h}{ }^{2}} \\
& +\frac{1}{2} \rho\left[C_{d s}{ }^{2} \frac{2}{\rho}\left(p_{s}-\frac{A_{s}{ }^{2} C_{d s}{ }^{2} p_{s}+A_{t}{ }^{2} C_{h}^{2} p_{h}}{A_{s}{ }^{2} C_{d s}{ }^{2}+A_{t}^{2} C_{h}{ }^{2}}\right)+2 g\left(r_{b}+\frac{l}{2} \psi^{2}\right)\right]\left(\frac{A_{R}^{\prime}}{A_{s}}\right) \xi
\end{aligned}
$$

The feedback valve spool forms dynamic balance under the action of pressure difference at both ends of the valve spool, feedback torque of the feedback rod and stiffness of feedback spring. The equation can be expressed as follows:

$$
\left(p_{c}-p_{h}\right) A_{c}-K_{f g}\left(r \psi+x_{c}\right)-2 K_{c} x_{c}=M_{c}+B_{c} \text { d }_{c}
$$

Where, $p_{c}$ is the buildup pressure $(\mathrm{Pa}) ; p_{h}$ is the return oil pressure $(\mathrm{Pa}) ; M_{c}$ is the mass of feedback spool $(\mathrm{kg}) ; K_{c}$ is the stiffness of the feedback spring $(\mathrm{N} / \mathrm{m}) ; B_{c}$ is the viscous damping of the feedback stage spool $(\mathrm{N} \cdot \mathrm{m} / \mathrm{rad} / \mathrm{s})$.

Under the action of control pressure, working pressure, oil return pressure, spring force and flow force, the main valve spool of power stage is in a state of dynamic balance. The equation can be expressed as follows:

$$
p_{c} A_{v}-p_{b} A_{b}-p_{h} A_{h}-F_{s}-F_{t}=M_{v}+B_{v} x_{v}^{\&}+K x_{v}+K x_{v 0}
$$

Where, $p_{b}$ is the brake pressure $(\mathrm{Pa}) ; A_{v}$ is the area of action of the control pressure $\left(\mathrm{m}^{2}\right) ; A_{b}$ is the area of action of the brake pressure $\left(\mathrm{m}^{2}\right) ; A_{h}$ is the feedback area of oil return pressure $\left(\mathrm{m}^{2}\right) ; F_{s}$ is the steady flow force $(\mathrm{N}) ; F_{t}$ is the transient flow force $(\mathrm{N}) ; M_{v}$ is the mass of power stage valve spool $(\mathrm{kg}) ; x_{v}$ is the displacement of power stage valve spool (m); $B_{v}$ is the viscous damping of power stage valve spool $(\mathrm{N} \cdot \mathrm{m} / \mathrm{rad} / \mathrm{s}) ; K$ is the spring stiffness of power stage valve spool $(\mathrm{N} / \mathrm{m}) ; \quad x_{v 0}$ is the initial compression of a power stage spring $(\mathrm{m})$.

The steady and transient flow force of the main valve spool are as follows:

$$
\begin{aligned}
& F_{s}=2 C_{v} C_{d} W \cos \theta \cdot \Delta p \cdot x_{v}=K_{f} x_{v} \\
& F_{t}=C_{d} W L \sqrt{2 \rho \Delta p} \frac{d x_{v}}{d t}=B_{f} \frac{d x_{v}}{d t}
\end{aligned}
$$

Where, $C_{v}$ is the coefficient of flow velocity; $C_{d}$ is the flow coefficient of servo valve; $W$ is the area gradient of the valve spool; $\theta$ is the efflux angle (rad); $\Delta p$ is the pressure difference of the valve port $(\mathrm{Pa}) ; K_{f}$ is the steady-state flow force stiffness $(\mathrm{N} / \mathrm{m}) ; B_{f}$ is the transient-state flow force stiffness $(\mathrm{N} / \mathrm{m} / \mathrm{s}) ; \quad L$ is the damping length (m).

\subsubsection{Mathematical model of load characteristics of PSVCS}

The oil flows into the rodless cavity of the actuator through the valve spool of power stage with $x_{v}>0$. The oil flows into the oil return cavity through the valve spool of power stage with $x_{v}<0$. Therefore, the load flow of power stage of pressure servo valve is as follows:

$$
Q_{L}=C_{d} W x_{v} \sqrt{\frac{2}{\rho}\left(\frac{1+\operatorname{sign}\left(x_{v}\right)}{2} p_{s}+\frac{-1+\operatorname{sign}\left(x_{v}\right)}{2} p_{h}-\operatorname{sign}\left(x_{v}\right) p_{b}\right)}
$$

According to the flow continuity equation, an equation can be obtained as follows: 


$$
Q_{L}=A_{g} \frac{d y}{d t}+\frac{V_{g b}}{\beta} \frac{\mathrm{d} p_{b}}{\mathrm{~d} t}+C_{b} p_{b}
$$

Where, $A_{g}$ is the effective area of the brake actuator piston $\left(\mathrm{m}^{2}\right) ; y$ is the displacement of the piston rod of the brake actuator $(\mathrm{m}) ; V_{g b}$ is the brake cavity composed of the rodless cavity of the brake actuator and the hydraulic pipe $\left(\mathrm{m}^{3}\right) ; C_{b}$ is the leakage coefficient of brake actuator $\left(\mathrm{m}^{3} / \mathrm{s} / \mathrm{Pa}\right) ; \quad \beta$ is the volumetric modulus of elasticity of oil.

\subsubsection{Mathematical model of oil return channel}

The oil return channel connected in series with direct-acting relief valve of the PSVCS is used to generate back pressure. Its material object and structure are shown in Fig. 6 and Fig. 7 respectively.
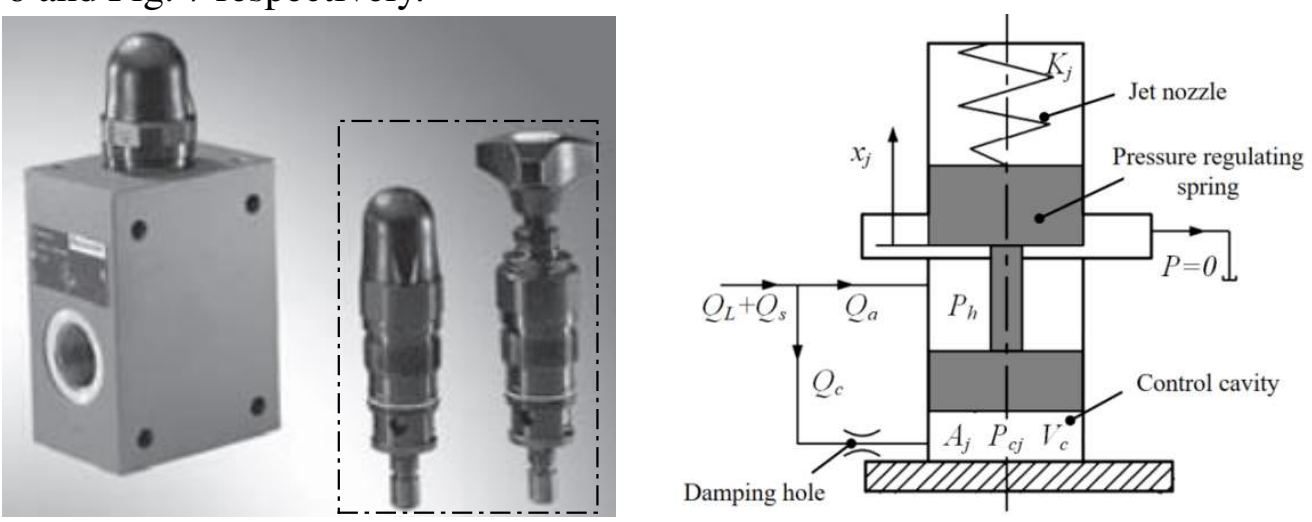

Fig. 6. Material object of direct-acting relief valve Fig. 7. Schematic diagram of relief valve follows:

The flow continuity equation of the valve spool of the oil return relief valve is as

$$
\&_{h}=\frac{\beta}{V_{h}}\left(Q_{a}-A\left(x_{j}\right) C_{d j} \sqrt{\frac{2}{\rho} p_{h}}\right)
$$

Where, $A\left(x_{j}\right)$ is the open area of relief valve port $\left(\mathrm{m}^{2}\right) ; C_{d j}$ is the flow coefficient of the relief valve; $Q_{a}$ is the flow of the relief valve $\left(\mathrm{m}^{3} / \mathrm{s}\right) ; V_{h}$ is the volume of the oil return cavity $\left(\mathrm{m}^{3}\right)$.

The valve spool structure of the direct-acting relief valve is a taper valve, and the specific structure is shown in Fig. 8.

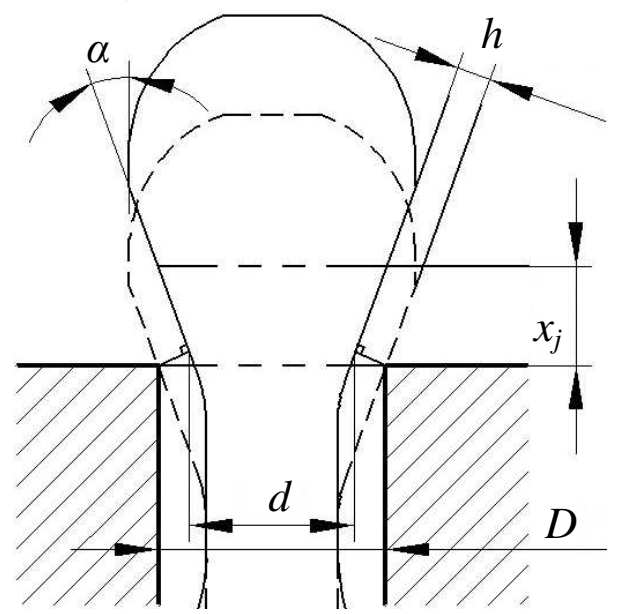

Fig. 8. Relative position of the spool and sleeve of the relief valve The flow area of the valve spool of relief valve is as follows: 


$$
\begin{aligned}
A\left(x_{j}\right) & =\pi d h=(D-2 h \cos \alpha) \pi h=\left(D-2 x_{j} \sin \alpha \cos \alpha\right) \pi x_{j} \sin \alpha \\
& =\left(1-\frac{x_{j}}{D} \sin 2 \alpha\right) \pi D x_{j} \sin \alpha
\end{aligned}
$$

Where, $D$ is the valve port diameter of relief valve $(\mathrm{m}) ; \alpha$ is the cone angle of valve spool $\left({ }^{\circ}\right)$.

Under the action of pressure difference, the flow through the damping hole is as follows:

$$
Q_{c}=\frac{\pi \delta^{4}}{128 \mu l}\left(p_{h}-p_{c j}\right)
$$

Where, $\delta$ is the diameter of relief valve damping hole $(\mathrm{m}) ; \mu$ is the dynamic viscosity of oil $\left(\mathrm{m}^{2} / \mathrm{s}\right) ; \quad l$ is the length of relief valve damping hole $(\mathrm{m})$.

The flow continuity equation of the control cavity is as follows:

$$
\&_{c j}=\frac{\beta}{V_{c j}}\left(Q_{c}-A_{j} \&_{J}\right)
$$

Where, $p_{c j}$ is the pressure of the control cavity of the relief valve $(\mathrm{Pa}) ; V_{c j}$ is the volume of the control cavity of the relief valve $\left(\mathrm{m}^{3}\right) ; Q_{c}$ is the flow of the control cavity of the relief valve $\left(\mathrm{m}^{3} / \mathrm{s}\right) ; A_{j}$ is the area of action of the pressure $\left(\mathrm{m}^{2}\right)$.

The relief valve spool is in dynamic balance under the action of oil return pressure, spring force, spool damping force and spool inertia force. The equation can be expressed as follows:

$$
p_{c j} A_{j}=M_{j}+B_{j} x_{j}^{\&}+K_{j} x_{j}+K_{j} x_{j 0}+k_{s} x_{j} p_{h}
$$

Where, $k_{s}$ is the steady-state flow force coefficient of relief valve spool $(\mathrm{N} / \mathrm{m} / \mathrm{Pa}) ; \quad M_{j}$ is the mass of the moving parts of the relief valve $(\mathrm{kg}) ; B_{j}$ is the damping coefficient of relief valve $(\mathrm{N} \cdot \mathrm{m} / \mathrm{rad} / \mathrm{s}) ; K_{j}$ is the pressure regulating spring stiffness of relief valve $(\mathrm{N} / \mathrm{m}) ; x_{j 0}$ is the initial compression of the pressure regulating spring of relief valve $(\mathrm{m})$.

Simplifying the system dynamics model, the transfer block diagram of the system from current input to brake pressure output can be obtained, as shown in Fig. 9.

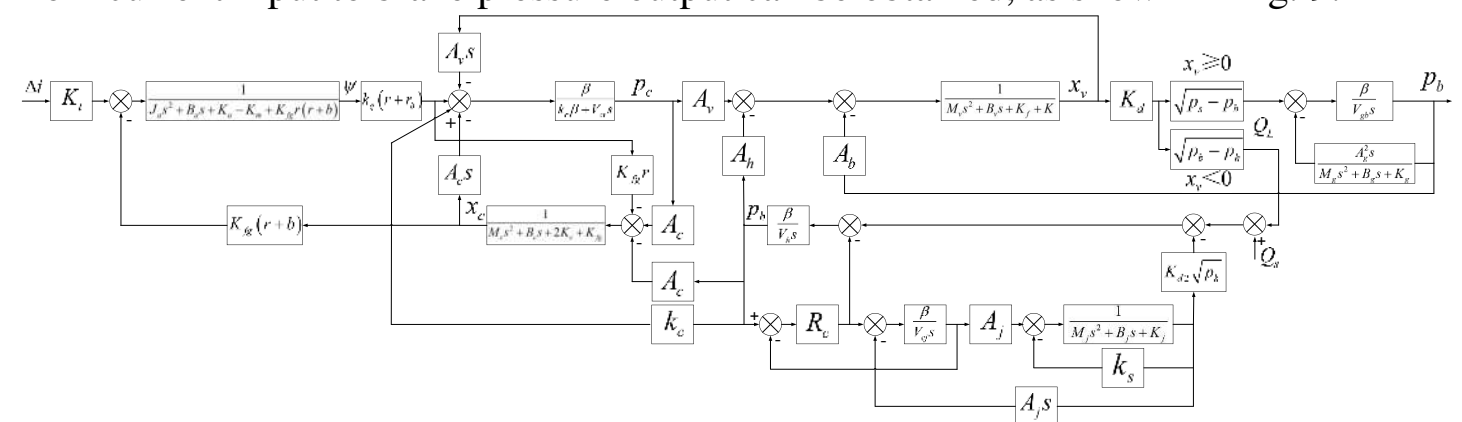

Fig. 9. The transfer block diagram of PSVCS

\section{Study on the influencing factors of nonlinear dynamics behavior of PSVCS}

\subsection{The dimensionless treatment of the dynamics model of the PSVCS}

The dynamic behavior of the PSVCS is analyzed from the perspective of nonlinear self-excited oscillation. It is concluded that the motion of the power stage 
valve spool of the brake pressure servo valve should be a steady periodic motion with constant magnitude and constant frequency, and the phase trajectory is an isolated closed curve in the phase plane. In order to verify this inference, this section will draw the phase trajectory of the power stage valve spool of the brake pressure servo valve in the phase plane with $x_{v}$ as the horizontal axis and $x_{v}$ as the vertical axis. However, due to the displacement of valve spool is generally very small, usually 0.5 $\mathrm{mm} \sim 1 \mathrm{~mm}$, and the shake speed of valve spool in the self-excited oscillation of high frequency is very fast. As a result, when $x_{v}$ and $x_{v}$ are drawn on the same plane, the range of curves drawn is too large or too small due to their dimensional differences, which is not conducive to the analysis of system characteristics. Meanwhile, from the perspective of the dynamic model itself, it describes the essential characteristics of the system, and the objective laws described by the model are not affected by dimension. Therefore, this section will conduct dimensionless treatment on the dynamics model of the PSVCS, and eliminate the adverse effects of dimension and order of magnitude in the process of in-depth discussion on the system dynamics behavior. follows:

The dynamics model established is treated by dimensionless treatment as

$$
\begin{gathered}
y_{1}=\psi, \quad y_{2}=t_{r e f} v_{1}, y_{3}=\frac{x_{c}}{x_{r e f}}, y_{4}=\frac{t_{r e f}}{x_{r e f}} v_{2}, y_{5}=\frac{x_{v}}{x_{r e f}}, \\
y_{6}=\frac{t_{r e f}}{x_{r e f}} v_{3}, y_{7}=\frac{y}{x_{r e f}}, y_{8}=\frac{t_{r e f}}{x_{r e f}} v_{4}, y_{9}=\frac{x_{j}}{x_{r e f}}, y_{10}=\frac{t_{r e f}}{x_{r e f}} v_{5}, \\
y_{11}=\frac{p_{c}}{P_{0}}, y_{12}=\frac{p_{b}}{P_{0}}, y_{13}=\frac{p_{h}}{P_{0}}, y_{14}=\frac{p_{c j}}{P_{0}} \\
x_{r e f}=\frac{A_{v} P_{0}}{K}, t_{r e f}=\sqrt{\frac{M_{v}}{K}}, \& \frac{t}{t_{r e f}}
\end{gathered}
$$

Where, $t_{\text {ref }}$ is the reciprocal of the natural frequency of the power stage valve spool $(\mathrm{s} / \mathrm{rad}) ; x_{\text {ref }}$ is the displacement of power stage valve spool under standard atmospheric pressure $(\mathrm{m}) ; P_{0}$ is standard atmospheric pressure $(\mathrm{Pa})$.

It should be noted that each dimensionless state variable is a function of dimensionless time $\delta$.

Substituting Equations (22) and (23) into the dynamic model, the dimensionless state space model of the brake servo valve can be obtained as follows.

$$
\begin{gathered}
\& \&=y_{6} \\
\&=y_{11}-\frac{A_{b}}{A_{v}} y_{12}-\frac{A_{h}}{A_{v}} y_{13}-\frac{B_{v}}{M_{v}} \sqrt{\frac{M_{v}}{K}} y_{6}-y_{1}-\frac{K_{f}}{K} y_{5}-\frac{K x_{v 0}}{A_{v} P_{0}} \\
\&=\frac{\beta}{V_{g b}} \frac{C_{d} W A_{v}}{K} \sqrt{\frac{2 M_{v} p_{0}}{K \rho}} y_{5} \sqrt{\frac{1+\operatorname{sgn}\left(y_{5}\right)}{2} p_{s 0}-\frac{1-\operatorname{sgn}\left(y_{5}\right)}{2} y_{13}-\operatorname{sgn}\left(y_{5}\right) y_{12}-\frac{\beta}{V_{g b}} \frac{A_{v} A_{g}}{K} y_{8}} \\
p_{s 0}=\frac{p_{s}}{p_{0}}, Q_{s 0}=\frac{Q_{s}}{Q_{0}}, \quad Q_{0}=C_{d} W \frac{A_{v} p_{0}}{K} \sqrt{\frac{2 p_{0}}{\rho}}
\end{gathered}
$$




\subsection{Phase plane analysis of PSVS}

When the brake pressure servo valve is working normally, the displacement of the valve spool of the power stage of the valve is the variation near zero position. Therefore, $y_{5}=0$ can be considered as the equilibrium point of the system. The phase plane of the system is drawn for the displacement of the dimensionless power stage valve spool $y_{5}$, the speed of the dimensionless power stage spool $y_{6}$ and the dimensionless brake pressure $y_{12}$, as shown in Fig. 10. The red curve is the phase plane of the constant magnitude oscillation of the dimensionless brake pressure, and the blue curve in Fig. 10-b is the projection of the phase trajectory in the plane $y_{5}-y_{6}$.

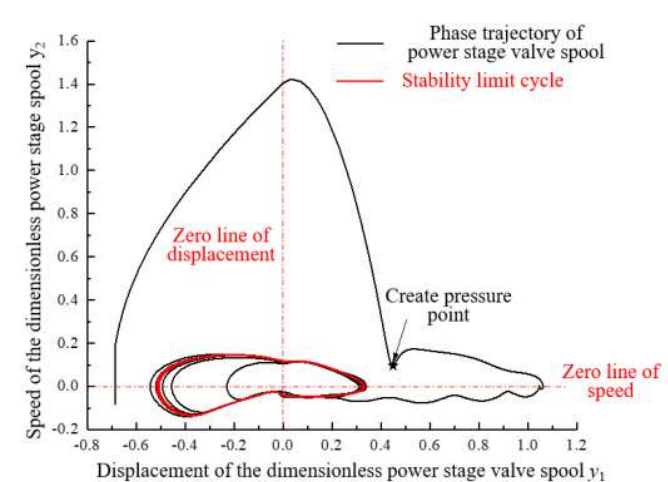

a) Phase plane of the power stage valve spool

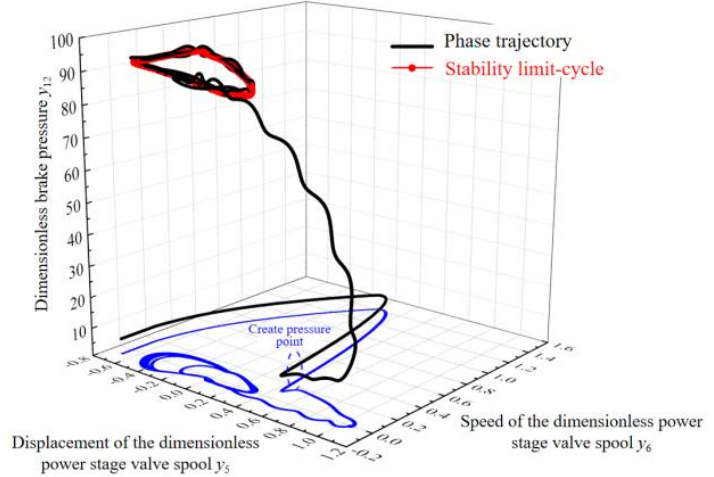

b) Phase plane of the power stage valve spool-brake pressure

Fig. 10. The phase planes of brake pressure under step signal

It can be seen that under the $40 \mathrm{~mA}$ step current signal, the PSVCS has a stable limit-cycle, which indicates that the movement of the system at the equilibrium point is a stable self-excited oscillation. Fig. 10-a shows that the stability limit-cycle formed by the movement of the power stage valve spool is not symmetric with respect to the zero line of displacement and the zero line of velocity. The area of the stability limit-cycle on the right side of the displacement zero line is less than that on the left side, indicating that the negative displacement of the power stage spool is greater than the positive displacement. The area of the stable limit-cycle above the zero line of speed is slightly larger than that below, indicating that the positive speed of the power stage valve spool is slightly greater than the negative speed. Therefore, during the movement process of the power stage valve spool, the time in the state of negative displacement is significantly longer than that in the state of positive displacement, resulting in the decrease of brake pressure and the rise of return oil pressure obviously, which leads to the positive feedback effect of return oil and forms the limit-cycle. In addition, the 3D phase trajectory in Fig.10-b shows that the initial segment of brake pressure isn't $0 \mathrm{MPa}$ (the blue projection line does not coincide with the black phase trajectory). This is because the brake cavity in the initial segment is connected with the oil return cavity. Therefore, the brake pressure set at this stage is the same as the preset oil return pressure in the simulation, namely $0.6 \mathrm{MPa}$, and the corresponding dimensionless quantity is 6 . Meanwhile, it can be seen that the brake pressure fluctuates up and down in a certain range with the different motion states of the power stage spool. 


\subsection{Influence of oil return cavity volume on nonlinear self-excited oscillation of PSVCS}

Since the volume of oil return cavity $V_{h}$ directly affects the pressure building process of oil return, this part will analyze the influence law of the phase trajectory of $V_{h}$ on the power stage valve spool of the brake pressure servo valve and the relief valve spool of oil return. Under the condition that $V_{h}$ is increased by $5 \%$ and $10 \%$, the simulation analysis is carried out on the MATLAB /Simulink platform, and the simulation time is 795.6. The phase trajectory of the power stage valve spool of the brake pressure servo valve and the phase trajectory of the relief valve spool of oil return are obtained and shown in Fig. 11. The stability limit-cycle in the figure is the phase trajectory in 795.6 (the same below).

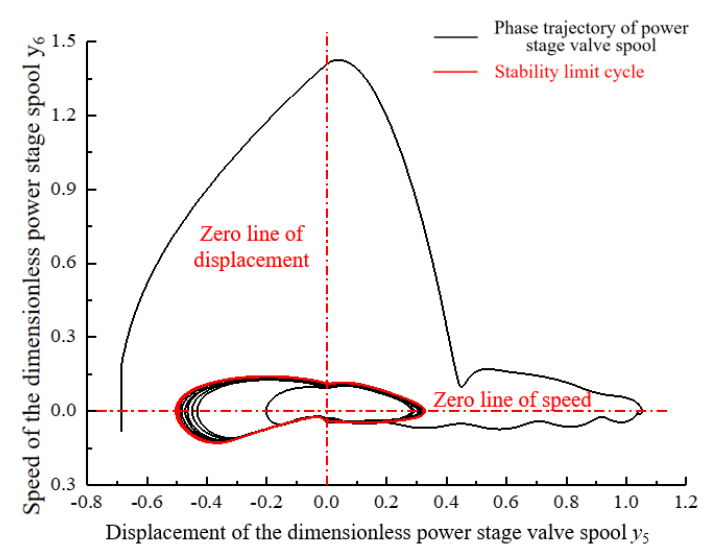

a) Phase plane of the power stage valve spool with $V_{h}$ increased by $5 \%$

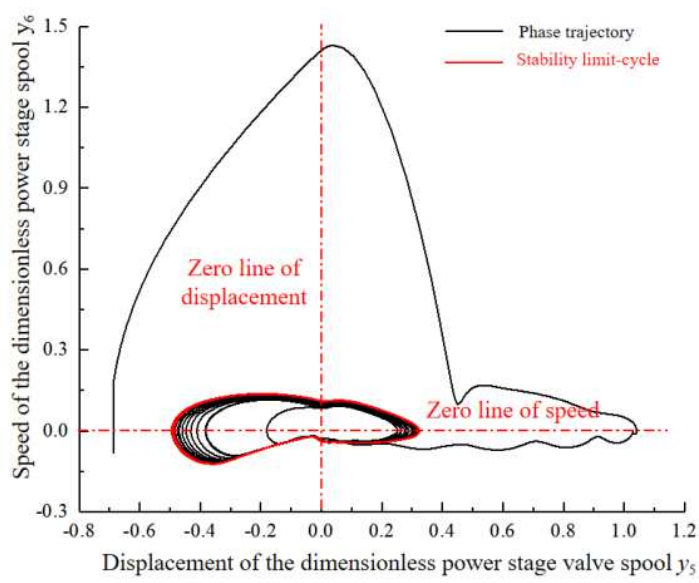

c) Phase plane of the power stage valve spool with $V_{h}$ increased by $10 \%$

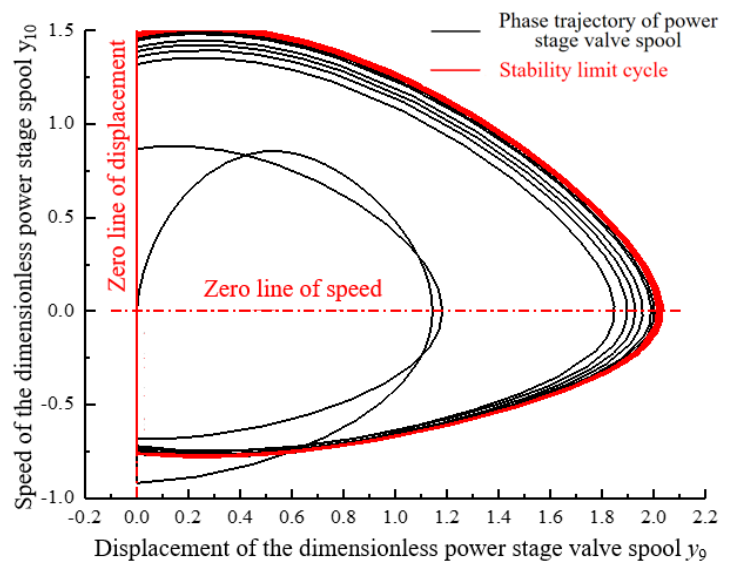

b) Phase plane of the relief valve spool with $V_{h}$ increased by $5 \%$

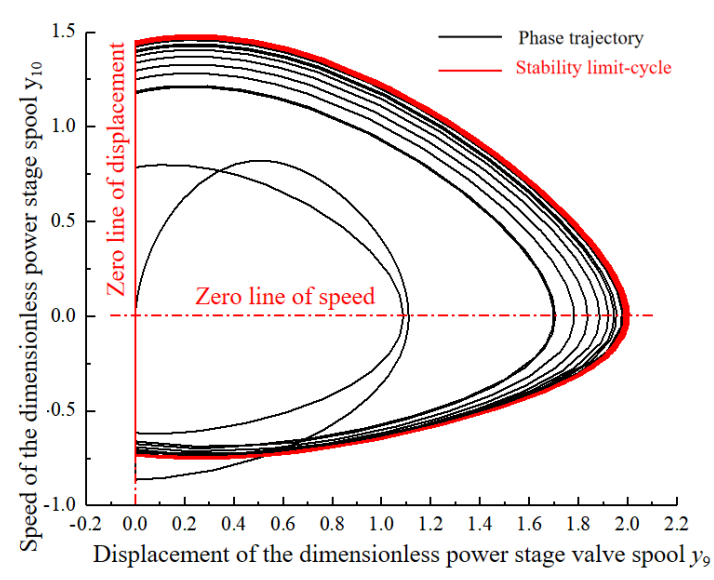

d) Phase plane of the relief valve spool with $V_{h}$ increased by $10 \%$

Fig. 11. The phase path with $V_{h}$ increased

As can be seen from Fig. 11, with the volume of oil return cavity $V_{h}$ increased, both the power stage valve spool and the relief valve spool need to go through a longer magnitude oscillation stage before a stable limit-cycle can finally be formed. The time domain curve of the dimensionless brake pressure is shown in Fig. 12 with $V_{h}$ increased by $5 \%$ and $10 \%$. 


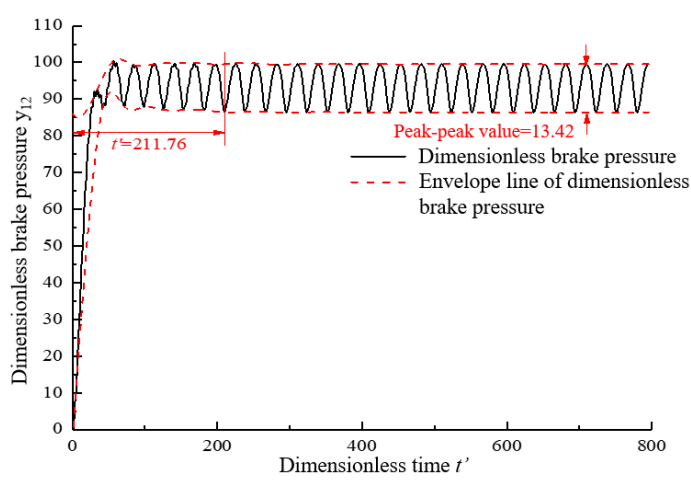

a) $V_{h}$ increased by $5 \%$

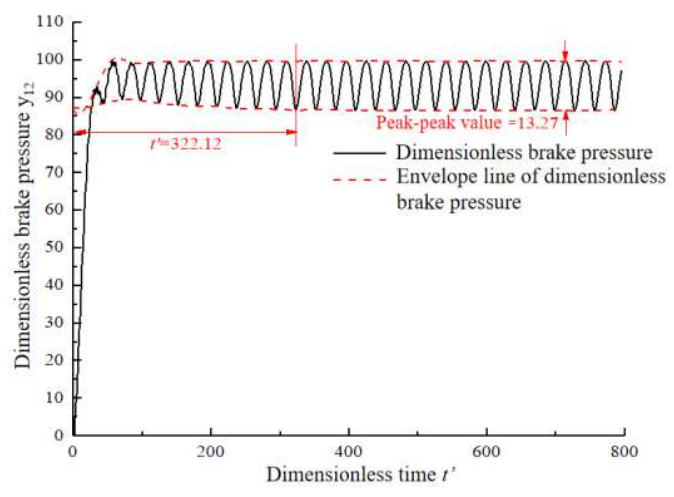

b) $V_{h}$ increased by $10 \%$

Fig. 12. The dimensionless brake pressure with $V_{h}$ increased

As shown in Fig. 12, with the volume of oil return cavity $V_{h}$ increased, the time for the brake pressure to form stable constant magnitude oscillation is gradually lengthened, and the peak value of the oscillation is gradually decreased. In the above process, since the volume of the brake cavity $V_{g b}$ doesn't change. Therefore, it can be speculated that the attenuation of oscillation magnitude and the extension of the formation time of stable oscillation are not caused by the dissipation of vibration energy of the brake pressure $p_{b}$, but by the attenuation of the return oil pressure $p_{h}$.

The analysis results of phase trajectory are shown in Fig. 13 with the volume of oil return cavity decreased.

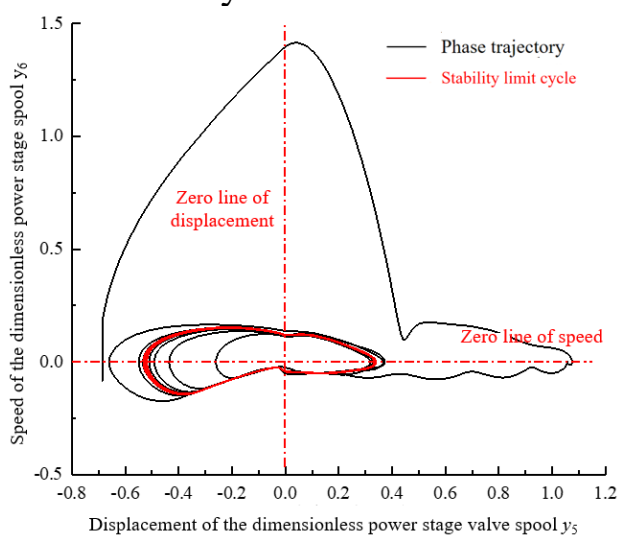

a) Phase plane of the power stage valve spool with $V_{h}$ decreased by $5 \%$

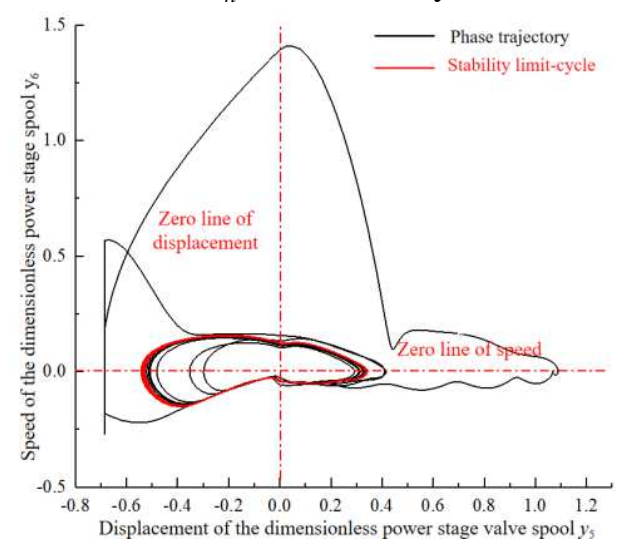

c) Phase plane of the power stage valve spool with $V_{h}$ decreased by $10 \%$

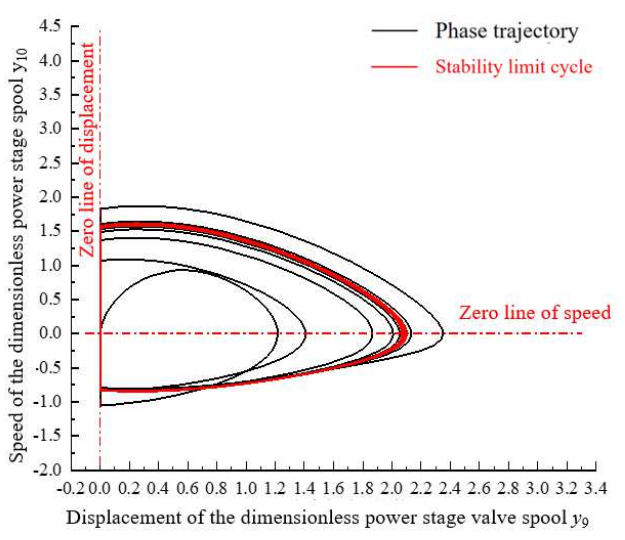

b) Phase plane of the relief valve spool with $V_{h}$ decreased by $5 \%$

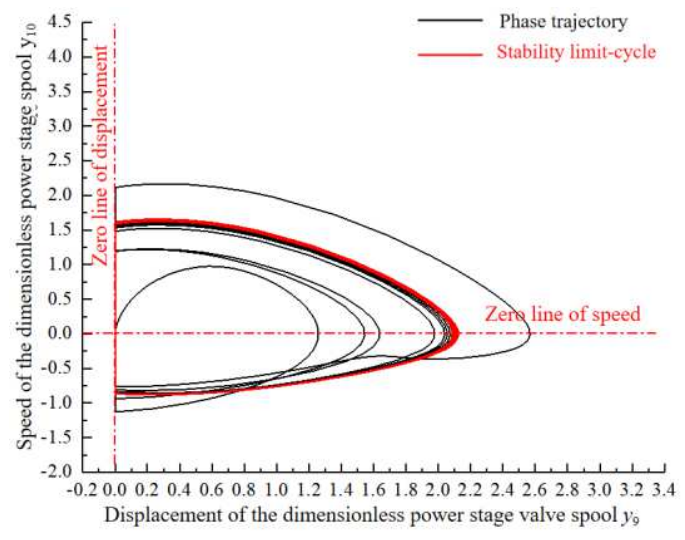

d) Phase plane of the relief valve spool with $V_{h}$ decreased by $10 \%$

Fig. 13. The phase trajectory with $V_{h}$ decreased 
As can be seen from Fig. 13, with the volume of oil return cavity $V_{h}$ decreased, both power stage valve spool and relief valve spool can rapidly form limit-cycles. Through comparative analysis, it can be seen that the negative displacement of the power stage valve spool increases before the formation of the stable limit-cycle with $V_{h}$ decreased, which indicates that the brake pressure will produce a greater decline. 14 ,

The above phenomenon can be clearly seen from the time domain curve in Fig.

the time required for the dimensionless brake pressure to form stable constant magnitude oscillation decreases gradually with $V_{h}$ decreased, but the oscillation peak value eventually formed shows a gradual upward trend, which is consistent with the results of phase plane analysis.

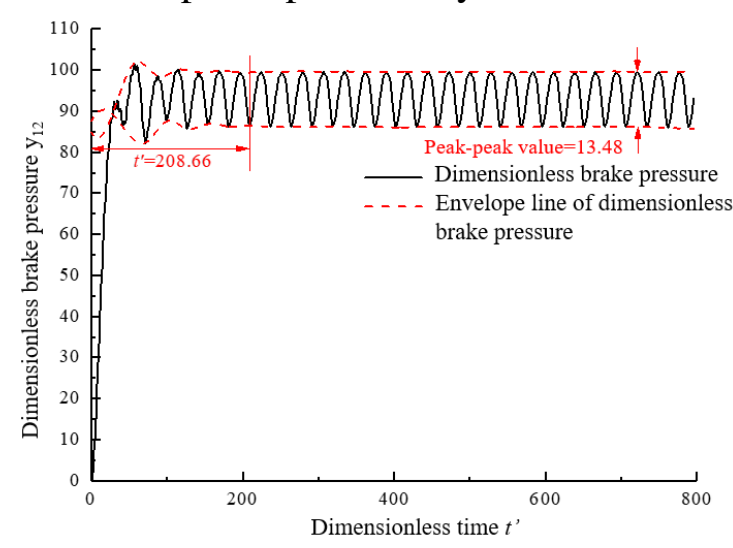

a) $V_{h}$ decreased by $5 \%$

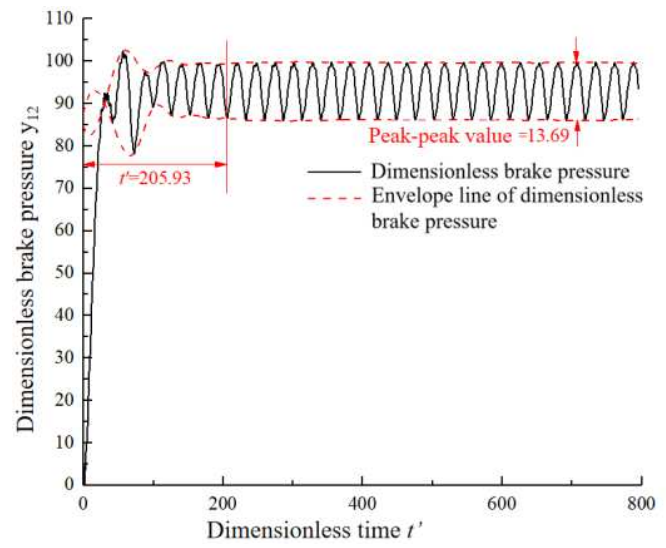

b) $V_{h}$ decreased by $10 \%$

Fig. 14. The dimensionless brake pressure with $V_{h}$ decreased

In order to further explain the effect of the volume of the brake cavity $V_{h}$ on the self-excited oscillation frequency of the system, the data of the brake pressure is analyzed by fast Fourier transform (FFT) when $V_{h}$ changes. The sampling frequency is $60 \mathrm{~Hz}$ and the frequency range is $0 \sim 100 \mathrm{~Hz}$, the obtained brake pressure FFT spectrum is shown in Fig. 15.

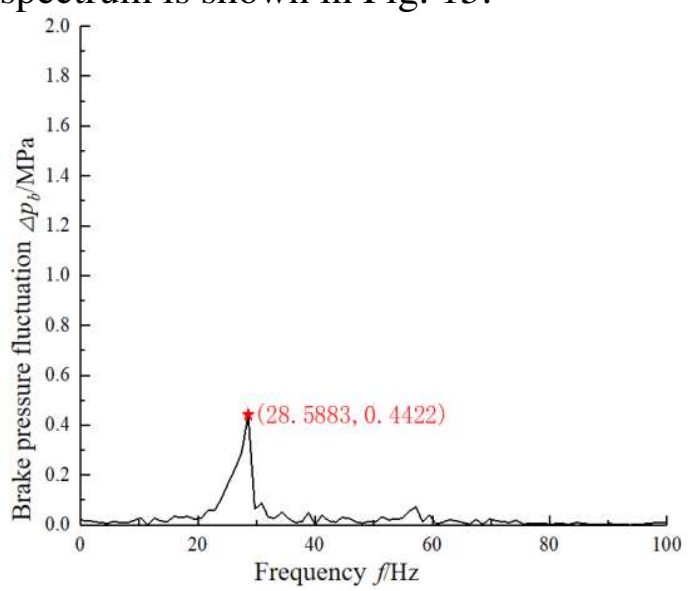

a) $V_{h}$ increased by $10 \%$

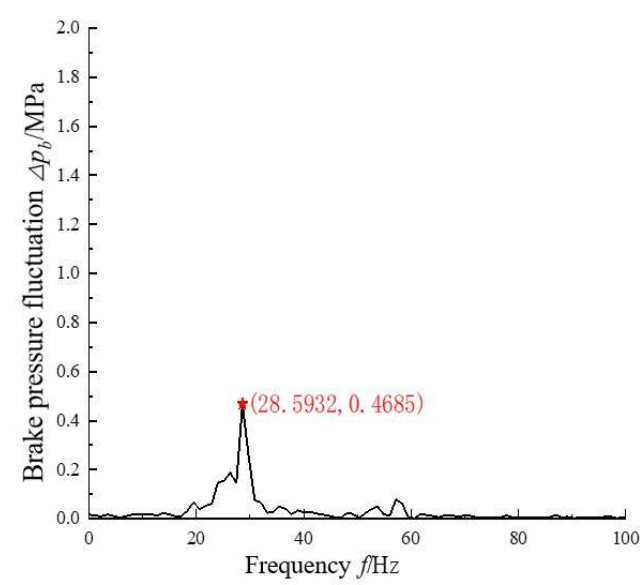

b) $V_{h}$ increased by $5 \%$ 


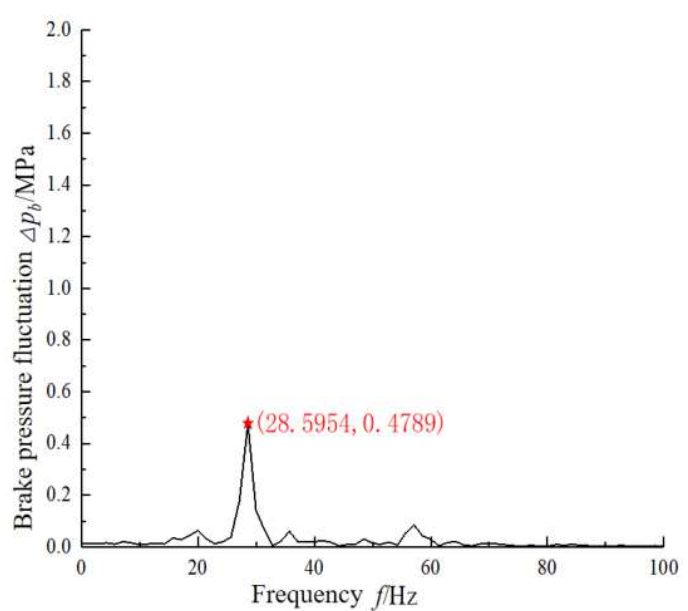

c) $V_{h}$ no changes

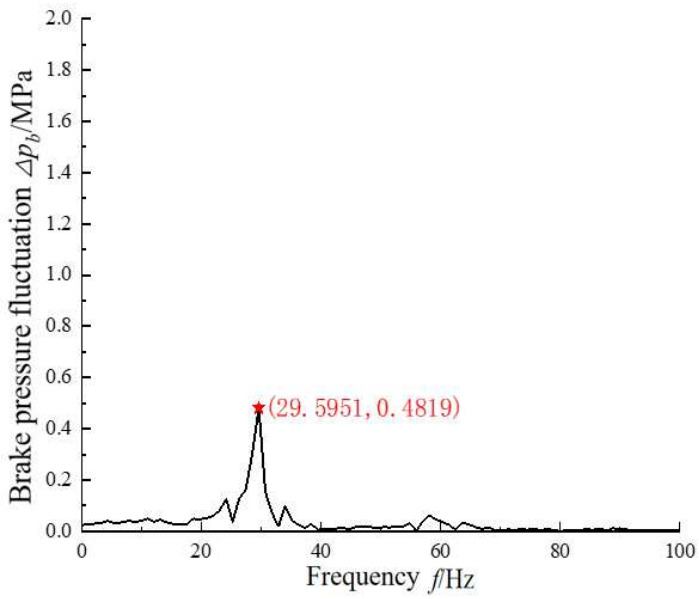

d) $V_{h}$ decreased by $5 \%$

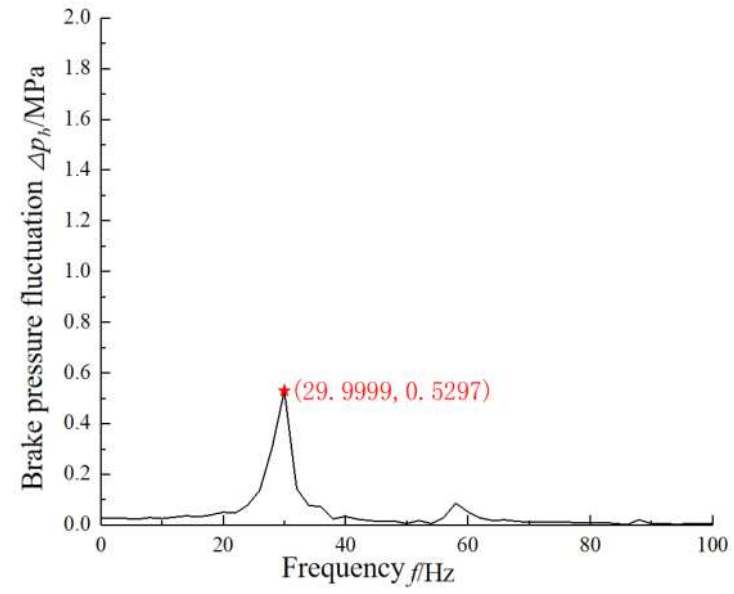

e) $V_{h}$ decreased by $10 \%$

Fig. 15. Brake pressure FFT spectrum with $V_{h}$ changed

As can be seen from Fig. 15, with the volume of oil return cavity $V_{h}$ decreased, the main frequency of brake pressure oscillation only slightly increases, but the oscillation magnitude corresponding to the main frequency significantly increases. Combined with the above analysis, it can be concluded that the volume of oil return cavity $V_{h}$ has an inversely proportional relationship with the magnitude of self-excited vibration of the PSVCS. That means increasing $V_{h}$ can decrease the magnitude of vibration. However, the volume of oil return cavity $V_{h}$ has little effect on the dominant frequency of self-excited vibration. The above phenomena can be explained as follows:

When the valve spool of the power stage moves to a negative direction, the brake cavity will discharge a certain flow to the return oil cavity under the action of pressure difference. At this point, the larger $V_{h}$ has a greater fluid impedance effect, it can better absorb the oil flow shock, decrease the oscillation magnitude of return oil pressure, make the change of return oil pressure $p_{h}$ more gentle, decrease the oscillation frequency of return oil pressure, the effect of positive feedback of return oil, and the vibration magnitude of brake pressure.

\section{Stability study on PSVC}

\subsection{Stability analysis of the prestage}

In this paper, the prestage of the brake pressure servo valve consists of two parts: 
the jet amplifier and the feedback stage. Its structure is shown in Fig. 16, and its working principle is similar to the two-stage electro-hydraulic servo valve with force feedback. Therefore, the stability of the prestage can be analyzed by referring to the stability analysis method of the two-stage electro-hydraulic servo valve. However, it is necessary to consider two special structures in the prestage of the brake pressure servo valve, namely: the initial state of the jet nozzle is not in the middle position of the two receiving holes but to the left receiving hole, and there is a spring with high stiffness at both ends of the feedback spool to establish the force balance relationship of the feedback spool.

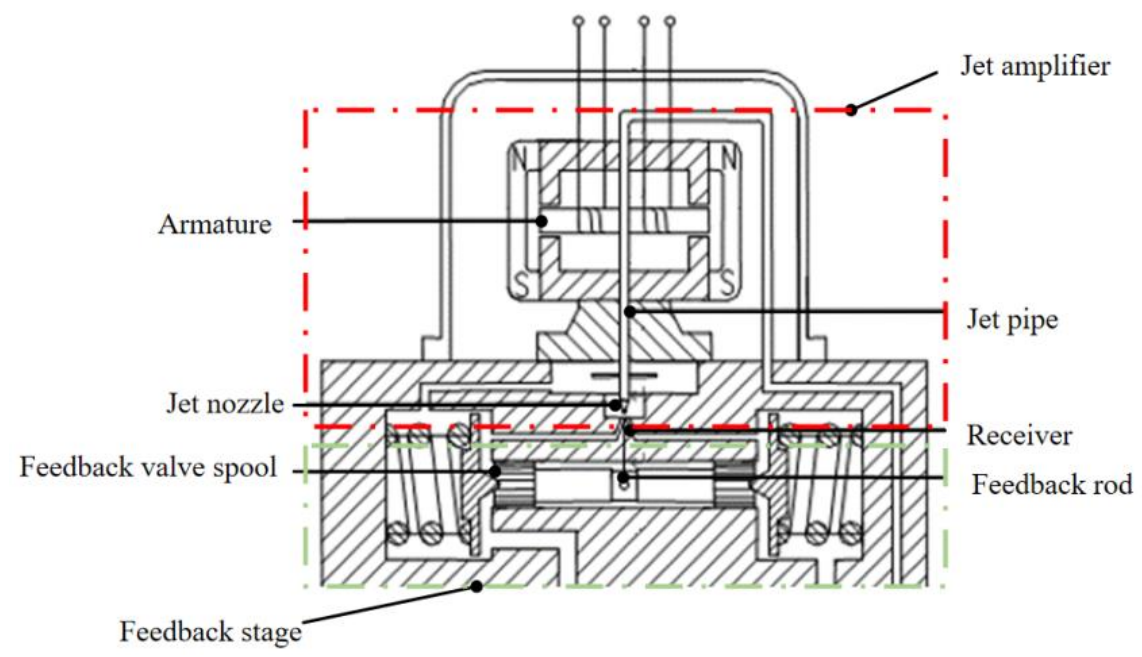

Fig. 16. The prestage structure of brake pressure servo valve

In the second section of this paper, the prestage dynamic model of the brake pressure servo valve has been established. Considering that the displacement of the valve spool is very small, the open-loop gain of the feedback loop constituted by its movement is very small compared with the open-loop gain of the force feedback loop constituted by the feedback stage, and its influence can be ignored. At the same time, in the normal working state, $p_{c}$ ? $p_{h}$, so the influence of oil return pressure feedback channel can also be ignored. After the above simplification, the prestage transfer block diagram of the brake pressure servo valve can be obtained, as shown in Fig. 17.

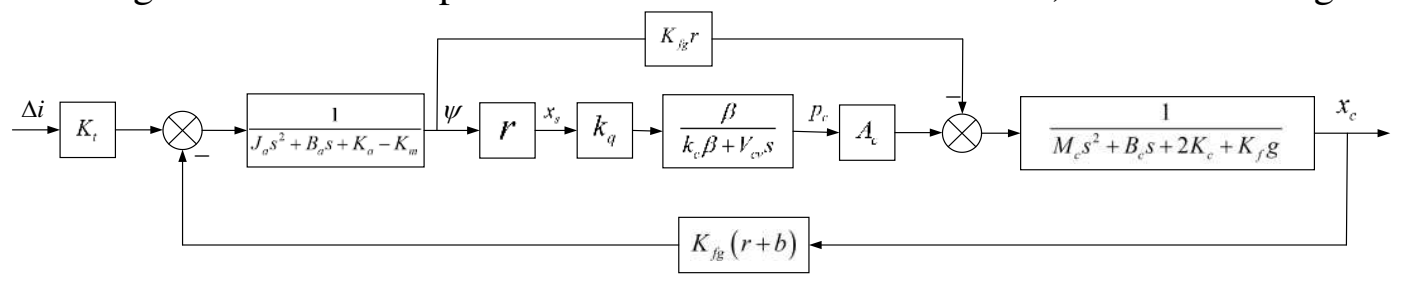

Fig. 17. The transfer block diagram of the brake pressure servo valve's prestage

In this paper, the Bode diagram is used to judge the stability of the system, but it should be noted that the concept of stability margin in the Bode criterion is for the minimum phase system. Because in the theory, only in the minimum phase system, can the gain and phase margin uniformly determine the stability of the system. Although the stability of non-minimum phase system can be analyzed by Bode diagram, the concept of stability margin does not exist for non-minimum phase system. Therefore, it is necessary to judge whether the system is a minimum phase system.

According to the system block diagram in Fig. 17, the open-loop Nyquist curve of prestage is solved, and the result is shown in Fig. 18. 


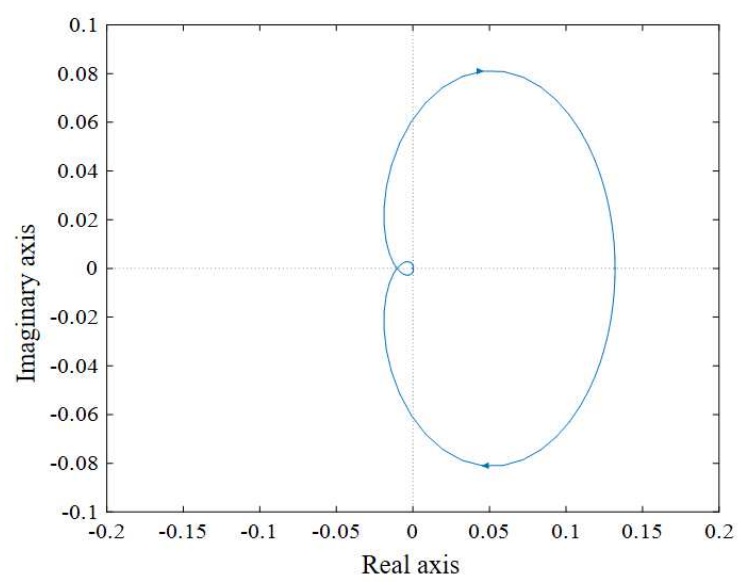

Fig. 18. The open-loop Nyquist curve of prestage

As can be seen from the Fig. 18, the prestage Nyquist curve doesn't surround the point $(-1, j 0)$, therefore, the prestage system doesn't have positive poles and is a minimum phase system. The stability and stability margin of the system can be judged according to the open-loop Bode diagram shown in Fig. 20.

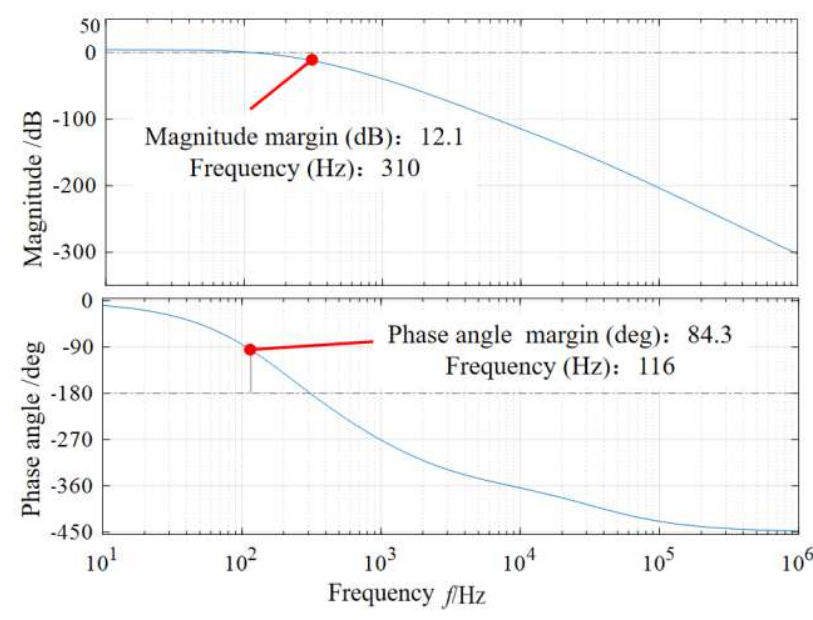

Fig. 20. The open-loop Bode diagram of the prestage of the brake pressure servo valve

Fig. 20 shows the Bode diagram phase-frequency curve of the PSVCS starts below the $0^{\circ}$ line and the number of positive traversing times is 0 . Moreover, in the frequency range of positive magnitude frequency characteristics of the open-loop logarithm, the phase-frequency curve doesn't traverse the $-180^{\circ}$ line. Therefore, the difference between the positive and negative traversing times of the $-180^{\circ}$ line of the phase-frequency curve is 0 . In the case that there is no positive open-loop pole in the system, the stability condition of the closed-loop system is satisfied, namely:

$$
n_{+}-n_{-}=P_{+} / 2=0
$$

Where, $\mathrm{n}+$ is the number of times that the open-loop phase-frequency curve is positive traversing the $-180^{\circ}$ line; $\mathrm{n}$ - is the number of times that the open-loop phase-frequency curve is negative traversing the $-180^{\circ}$ line; $\mathrm{P}+$ is the number of open-loop positive poles.

It can be seen that the prestage of the brake pressure servo valve is stable and has a large magnitude margin $(12.1 \mathrm{~dB}>6 \mathrm{~dB})$ and phase angle margin( $84.3 \mathrm{deg}>30 \mathrm{deg})$, and it can keep stable under certain external disturbances. 


\subsection{Stability analysis of the power stage}

According to the dynamics model of PSVCS, the transfer block diagram of the power stage from the buildup pressure to the brake pressure is obtained in Fig. 21.

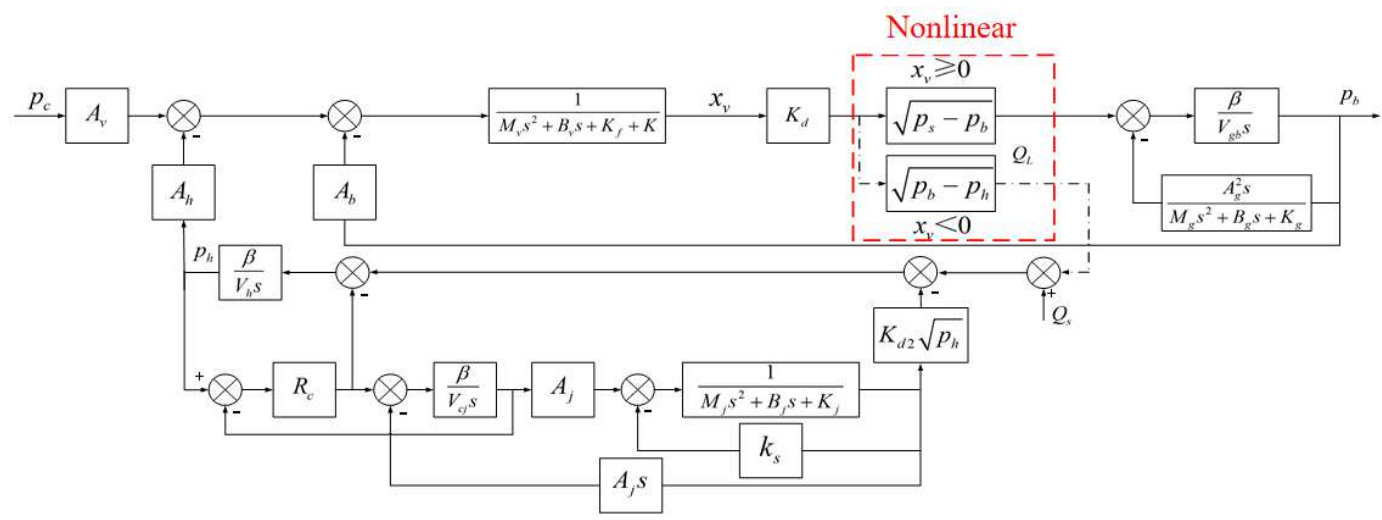

Fig. 21. The transfer block diagram of the power stage of PSVCS

It can be seen that the power stage of the PSVCS is a high-order system, and there are complex feedback loops, including nonlinear links. Therefore, the system stability can not be directly judged by the method of linear system frequency characteristic analysis. In the process of switching between the two sides of the power stage spool of the brake pressure servo valve at zero position, the flow direction switching is the key factor that causes the vibration of PSVCS. Therefore, the positive and negative displacements of the power stage valve spool should be analyzed as two independent working conditions respectively.

It is noted that there are square root operations in the flow calculation of the power stage valve spool, but they are not the essential nonlinear links that affect the system characteristics. Therefore, it can be simplified by the method of small deviation linearization, namely:

$$
\begin{gathered}
Q_{L}=k_{q v} x_{v}-k_{c v} p_{L} \\
p_{L}=\frac{1+\operatorname{sign}\left(x_{v}\right)}{2} p_{s}-\frac{1-\operatorname{sign}\left(x_{v}\right)}{2} p_{h}-\operatorname{sign}\left(x_{v}\right) p_{b}
\end{gathered}
$$

After the above simplification, it is necessary to establish the system control block diagram respectively according to the positive/negative state of the power stage valve spool displacement.

The oil from the oil source flows into the brake cavity through the valve opening of the power stage valve spool with $x_{v} \geqslant 0$. The oil return pressure $p_{h}$ can be considered to be a constant value of $0.6 \mathrm{MPa}$. At this time, the transfer block diagram of the system is shown in Fig. 22.

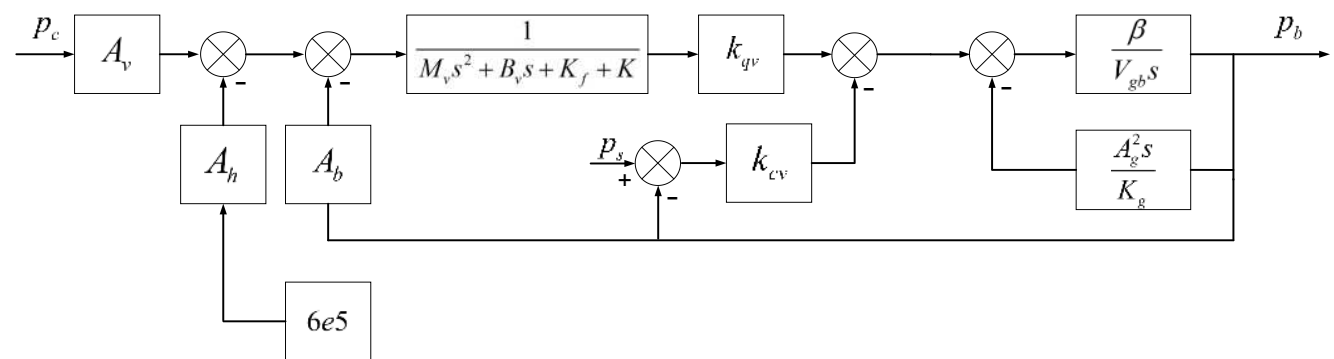

Fig. 22. The transfer block diagram of the PSVCS $p_{c}-p_{b}$ with $x_{v} \geqslant 0$ 
The oil from the brake cavity flows into the oil return channel through the valve opening of the power stage valve spool with $x_{v}<0$. At this time, the transfer block diagram of the system is shown in Fig. 23.

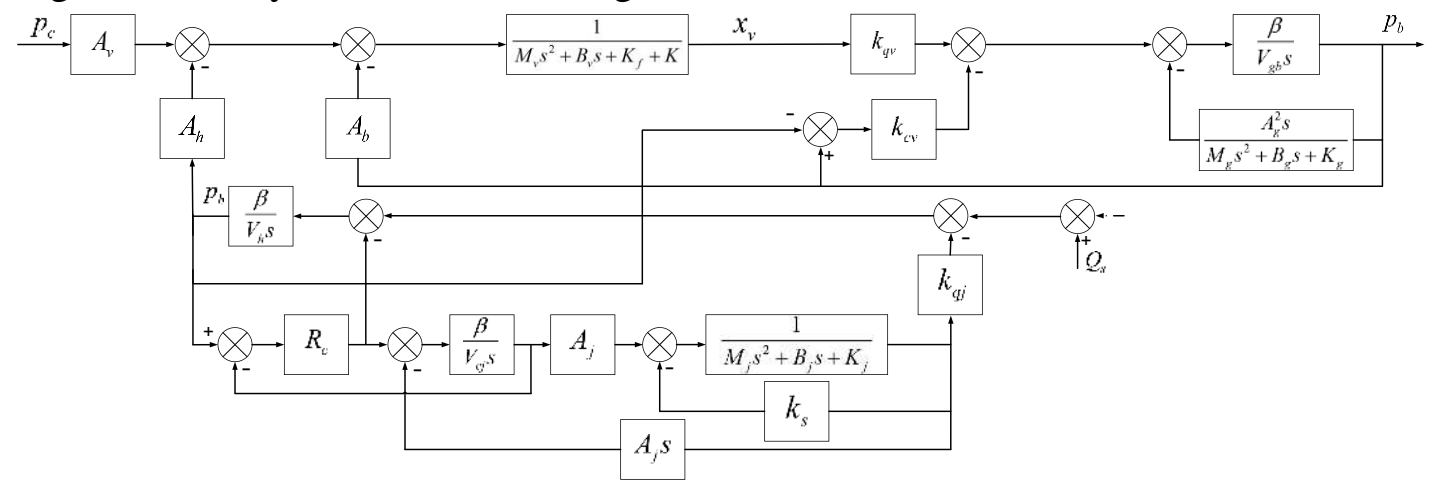

Fig. 23. The transfer block diagram of the PSVCS $p_{c}-p_{b}$ with $x_{v}<0$

\subsubsection{Determination of linearization parameters in transfer block diagram}

In the transfer block diagram of the PSVCS, linear flow gain coefficient $k_{q v}$ and flow-pressure gradient $k_{c v}$ are used to calculate the load flow of the power stage valve spool of brake pressure servo valve. These two parameters are obtained by calculating the partial derivative of the load flow of the power stage of the brake pressure servo valve with respect to the spool displacement and the load pressure difference, namely:

$$
\begin{aligned}
& k_{q v}=\frac{\partial Q_{L}}{\partial x_{v}}=C_{d} W \sqrt{\frac{p_{L}}{\rho}} \\
& k_{c v}=-\frac{\partial Q_{L}}{\partial p_{L}}=\frac{C_{d} W x_{v}}{2 \sqrt{\rho p_{L}}}
\end{aligned}
$$

It can be seen that the above linearization parameters are the functions related to the load pressure difference and displacement of the power stage valve spool, and the load pressure difference will change with the switch of displacement direction. Therefore, first of all, it is necessary to clarify the possible value range of the load pressure difference $p_{L}$ when the displacement of the power stage valve spool changes.

Limited by the structure of the pressure servo valve, the displacement range of the power stage spool is $-0.5 \mathrm{~mm} \leqslant x_{v} \leqslant 1.5 \mathrm{~mm}$.

When the range of valve spool displacement is $0 \mathrm{~mm} \leqslant x_{v} \leqslant 1.5 \mathrm{~mm}$, the load pressure difference $p_{L}=p_{s}-p_{b}$. While the oil supply pressure $p_{s}=15 \mathrm{MPa}$, the maximum of brake pressure $p_{b \max } \approx 9.8 \mathrm{MPa}$. So the minimum of brake pressure $p_{b \text { min }} \approx 0.6 \mathrm{MPa}$, the range of load pressure difference is $5.2 \mathrm{MPa} \leqslant p_{L} \leqslant 14.4 \mathrm{MPa}$.

When the range of valve spool displacement is $-0.5 \mathrm{~mm} \leqslant x_{v}<0 \mathrm{~mm}$, the load pressure difference $p_{L}=p_{b}-p_{h}$. While the oil return pressure $p_{h}=0.6 \mathrm{MPa}$, the brake pressure $p_{b}=9.8 \mathrm{MPa}$, so the load pressure difference is $0 \mathrm{MPa} \leqslant p_{L} \leqslant 9.2 \mathrm{MPa}$.

It is necessary to pay attention to the value of the displacement of the power 
stage valve spool $x_{v}$. Although the mechanical limit of the power stage valve spool is $-0.5 \mathrm{~mm} \leqslant x_{v} \leqslant 1.5 \mathrm{~mm}$, when the pressure servo valve is in normal operation, its valve spool is moving around the near zero position, and take its value as $-0.45 \mathrm{~mm} \leqslant x_{v} \leqslant 0.45 \mathrm{~mm}$.

After determining the value range of power stage valve spool displacement $x_{v}$ and load pressure difference $p_{L}$, the linearization coefficient of power stage valve spool can be solved according to Equations (31) and (32). At the same time, in the process of establishing the transfer function of the PSVCS, the steady-state flow force stiffness $K_{f}$ is also introduced as follows:

$$
K_{f}=2 C_{\nu} C_{d} W \cos \theta \cdot p_{L}
$$

In the above range of load pressure difference, the $K_{f}$ will also change accordingly.

Because the power stage valve spool only oscillates slightly near zero position when the displacement of the power stage valve spool $x_{v}$ is in normal operation. Therefore, when the value of $x_{v}$ is near zero position, the value step of spool displacement and load pressure difference should be as small as possible. So the value array of power stage valve spool displacement $x_{v}$ and load pressure difference $p_{L}$ is shown in Table 1.

Table 1 The value array of $x_{v}$ and $p_{L}$

\begin{tabular}{|c|c|c|c|c|c|c|c|c|c|c|c|c|c|c|c|c|c|c|c|c|c|}
\hline$x_{\downarrow} / \mathrm{mm}$ & 5 & 5.5 & 6 & 6.5 & 7 & 7.5 & 8 & 8.5 & 9 & 9.5 & 10 & 10.5 & 11 & 11.5 & 12 & 12.5 & 13 & 13.5 & 14 & 14.5 & 15 \\
\hline 0.45 & $\sqrt{ }$ & & & & $\sqrt{ }$ & & & & $\sqrt{ }$ & & & & $\sqrt{ }$ & & & & $\sqrt{ }$ & & & & $\sqrt{ }$ \\
\hline 0.2 & $\sqrt{ }$ & $\sqrt{ }$ & $\sqrt{ }$ & $\sqrt{ }$ & $\sqrt{ }$ & $\sqrt{ }$ & $\sqrt{ }$ & $\sqrt{ }$ & $\sqrt{ }$ & $\sqrt{ }$ & $\sqrt{ }$ & $\sqrt{ }$ & $\sqrt{ }$ & $\sqrt{ }$ & $\sqrt{ }$ & $\sqrt{ }$ & $\sqrt{ }$ & $\sqrt{ }$ & $\sqrt{ }$ & $\sqrt{ }$ & $\sqrt{ }$ \\
\hline 0.15 & $\sqrt{ }$ & $\sqrt{ }$ & $\sqrt{ }$ & $\sqrt{ }$ & $\sqrt{ }$ & $\sqrt{ }$ & $\sqrt{ }$ & $\sqrt{ }$ & $\sqrt{ }$ & $\sqrt{ }$ & $\sqrt{ }$ & $\sqrt{ }$ & $\sqrt{ }$ & $\sqrt{ }$ & $\sqrt{ }$ & $\sqrt{ }$ & $\sqrt{ }$ & $\sqrt{ }$ & $\sqrt{ }$ & $\sqrt{ }$ & $\sqrt{ }$ \\
\hline 0.1 & $\sqrt{ }$ & $\sqrt{ }$ & $\sqrt{ }$ & $\sqrt{ }$ & $\sqrt{ }$ & $\sqrt{ }$ & $\sqrt{ }$ & $\sqrt{ }$ & $\sqrt{ }$ & $\sqrt{ }$ & $\sqrt{ }$ & $\sqrt{ }$ & $\sqrt{ }$ & $\sqrt{ }$ & $\sqrt{ }$ & $\sqrt{ }$ & $\sqrt{ }$ & $\sqrt{ }$ & $\sqrt{ }$ & $\sqrt{ }$ & $\sqrt{ }$ \\
\hline 0.05 & $\sqrt{ }$ & $\sqrt{ }$ & $\sqrt{ }$ & $\sqrt{ }$ & $\sqrt{ }$ & $\sqrt{ }$ & $\sqrt{ }$ & $\sqrt{ }$ & $\sqrt{ }$ & $\sqrt{ }$ & $\sqrt{ }$ & $\sqrt{ }$ & $\sqrt{ }$ & $\sqrt{ }$ & $\sqrt{ }$ & $\sqrt{ }$ & $\sqrt{ }$ & $\sqrt{ }$ & $\sqrt{ }$ & $\sqrt{ }$ & $\sqrt{ }$ \\
\hline
\end{tabular}

a) $x_{v} \geq 0$

\begin{tabular}{|c|c|c|c|c|c|c|c|c|c|c|c|c|c|c|c|c|c|c|}
\hline$x_{v} / \mathrm{mm}$ & 0.5 & 1 & 1.5 & 2 & 2.5 & 3 & 3.5 & 4 & 4.5 & 5 & 5.5 & 6 & 6.5 & 7 & 7.5 & 8 & 8.5 & 9 \\
\hline-0.05 & $\sqrt{ }$ & $\sqrt{ }$ & $\sqrt{ }$ & $\sqrt{ }$ & $\sqrt{ }$ & $\sqrt{ }$ & $\sqrt{ }$ & $\sqrt{ }$ & $\sqrt{ }$ & $\sqrt{ }$ & $\sqrt{ }$ & $\sqrt{ }$ & $\sqrt{ }$ & $\sqrt{ }$ & $\sqrt{ }$ & $\sqrt{ }$ & $\sqrt{ }$ & $\sqrt{ }$ \\
\hline-0.1 & $\sqrt{ }$ & $\sqrt{ }$ & $\sqrt{ }$ & $\sqrt{ }$ & $\sqrt{ }$ & $\sqrt{ }$ & $\sqrt{ }$ & $\sqrt{ }$ & $\sqrt{ }$ & $\sqrt{ }$ & $\sqrt{ }$ & $\sqrt{ }$ & $\sqrt{ }$ & $\sqrt{ }$ & $\sqrt{ }$ & $\sqrt{ }$ & $\sqrt{ }$ & $\sqrt{ }$ \\
\hline-0.15 & $\sqrt{ }$ & $\sqrt{ }$ & $\sqrt{ }$ & $\sqrt{ }$ & $\sqrt{ }$ & $\sqrt{ }$ & $\sqrt{ }$ & $\sqrt{ }$ & $\sqrt{ }$ & $\sqrt{ }$ & $\sqrt{ }$ & $\sqrt{ }$ & $\sqrt{ }$ & $\sqrt{ }$ & $\sqrt{ }$ & $\sqrt{ }$ & $\sqrt{ }$ & $\sqrt{ }$ \\
\hline-0.2 & $\sqrt{ }$ & $\sqrt{ }$ & $\sqrt{ }$ & $\sqrt{ }$ & $\sqrt{ }$ & $\sqrt{ }$ & $\sqrt{ }$ & $\sqrt{ }$ & $\sqrt{ }$ & $\sqrt{ }$ & $\sqrt{ }$ & $\sqrt{ }$ & $\sqrt{ }$ & $\sqrt{ }$ & $\sqrt{ }$ & $\sqrt{ }$ & $\sqrt{ }$ & $\sqrt{ }$ \\
\hline-0.45 & & & & $\sqrt{ }$ & & & & $\sqrt{ }$ & & & & $\sqrt{ }$ & & & & $\sqrt{ }$ & & \\
\hline
\end{tabular}

b) $x_{v}<0$

\subsubsection{Stability analysis of PSVCS}

Bode diagram analysis as a kind of linear system theory, logarithmic magnitude frequency characteristic analysis method does not apply to most of the nonlinear system analysis. In this paper, although the PSVCS is a typical nonlinear system, its input signal and the system initial state is relatively fixed, and the role of the nonlinear link is clear. Therefore, the concept of "cluster" is introduced in this paper to draw the Bode diagram bundle when the structural parameters change within the movement range of the power stage valve spool, and to analyze the stability of the system and the influence of the parameters on the stability and stability margin. 
(1) Stability analysis of power stage with $x_{v}>0$

According to the system block diagram in Fig. 22, the open-loop frequency characteristic curves of the power stage valve spool under different positive displacement are solved with $x_{v}>0$, and the results are shown in Fig. 24 .

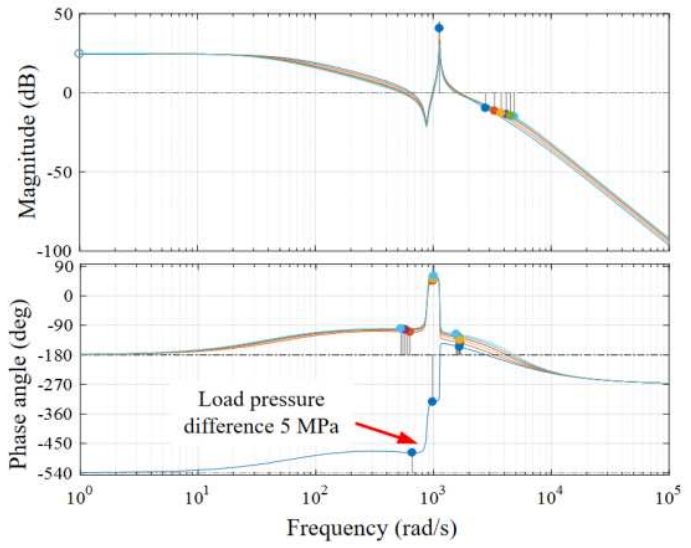

a) $x_{v}=0.45 \mathrm{~mm}$

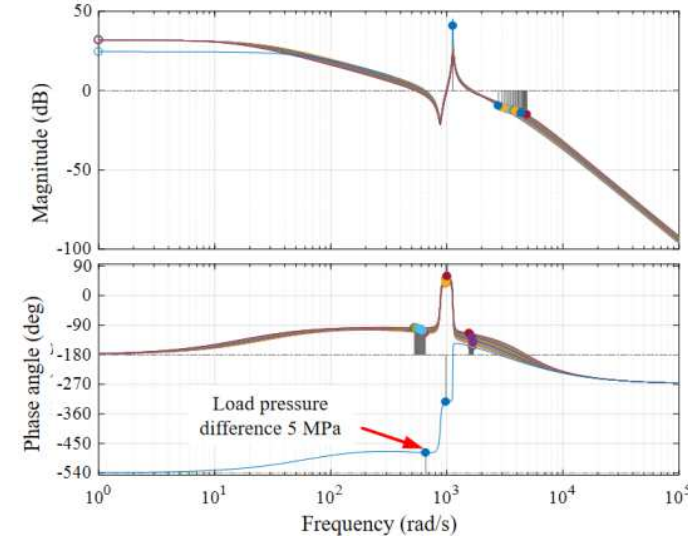

b) $x_{v}=0.2 \mathrm{~mm}$

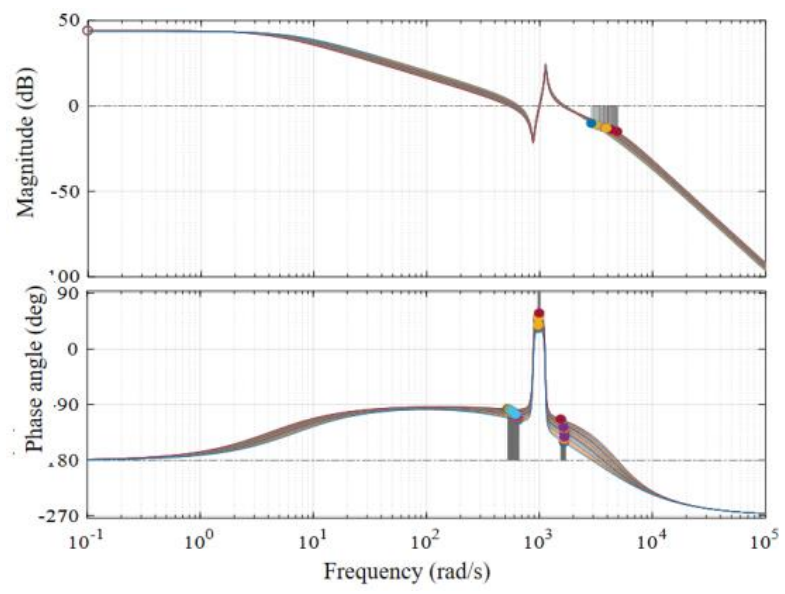

c) $x_{v}=0.05 \mathrm{~mm}$

Fig. 24. The open-loop Bode curve cluster of the power stage valve spool with $x_{v}>0$

In order to judge whether the PSVCS is the minimum phase system with $x_{v}>0$, the load pressure difference $p_{L}$ is respectively $5 \mathrm{MPa}, 7 \mathrm{MPa}, 9 \mathrm{MPa}, 11 \mathrm{MPa}, 13$ $\mathrm{MPa}$ and $15 \mathrm{MPa}$, and the open-loop Nyquist curve bundle is drawn by MATLAB. Due to the limitation of paper length, only the curves for the following two different cases are shown in Fig. 25:

(1) The valve spool displacement of the power stage is $x_{v}=0.05 \mathrm{~mm}$, and the load pressure difference $p_{L}$ is different;

(2) The load pressure difference is $p_{L}=7 \mathrm{MPa}$, and the displacement of the power stage spool is different. 


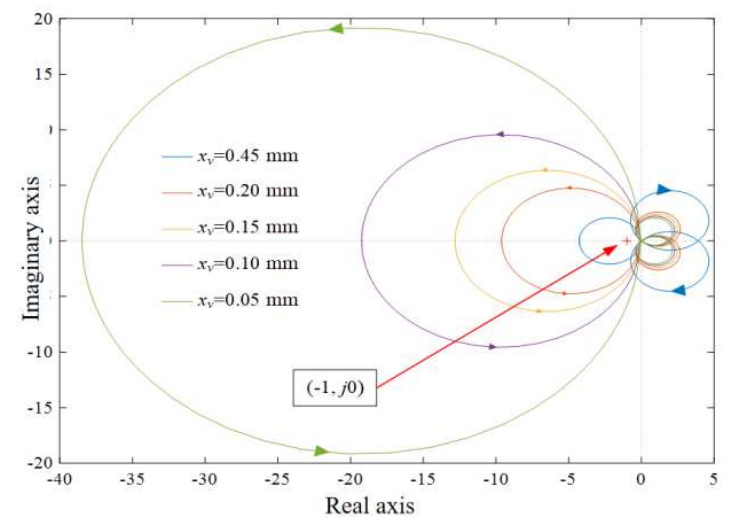

a) $x_{v}=0.05 \mathrm{~mm}$

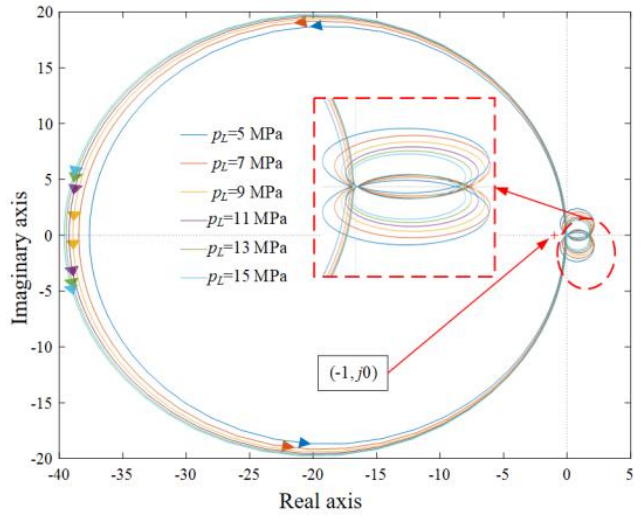

b) $p_{L}=7 \mathrm{MPa}$

Fig. 25. The open-loop Nyquist curve cluster under different operating conditions with $x_{v}>0$

According to the open-loop Nyquist curve of the power stage, it can be seen that under all working conditions of $x_{v}>0$, the open-loop Nyquist curve of the power stage is surrounded by $(-1, j 0)$, the power stage system has an open-loop positive pole and is a non-minimum phase system. So the following conclusion can be drawn:

In the case of $x_{v}>0$, the power stage system is a non-minimum phase system and the system open loop is not stable. The phase frequency curve cluster in the Bode diagram of the power stage system starts from the $-180^{\circ}$ line, as positive traversing $1 / 2$ times. In the frequency range where the open loop logarithmic magnitude frequency characteristic is positive, the open-loop logarithmic phase frequency curve has no other phenomenon of traversing the $-180^{\circ}$ line. Therefore, the difference between the positive and negative traversing times of the $-180^{\circ}$ line of the phase frequency curve is $1 / 2$. The stability condition of closed-loop system is satisfied when there is only one open-loop positive pole. In this case of $x_{v}>0$, the system is closed-loop stable.

When the displacement of the power stage valve spool is at the far end of zero position $\left(0.2 \mathrm{~mm} \leqslant x_{v} \leqslant 0.45 \mathrm{~mm}\right)$, the phase angle of the PSVCS has an obvious lag, which will disappear when the load pressure difference increases. When $x_{v}=0.45 \mathrm{~mm}$ and $x_{v}=0.2 \mathrm{~mm}, p_{L}>5 \mathrm{MPa}$ and the large phase angle lag disappears (Fig. 24-a, Fig. 24-b). This phenomenon is caused by two reasons: the non-minimum phase system itself has a large phase angle lag, in the case of small pressure difference, the valve port flow of the power stage valve spool is small, under the capacitive effect of the brake cavity, the pressure response is very slow.

(2) Stability analysis of power stage with $x_{v}<0$

When the power stage valve spool is in a negative displacement state, according to the system block diagram in Fig. 23, the open-loop frequency characteristic curves of the power stage system under different negative displacements are obtained as shown in Fig. 26, and then determine whether the power stage system is the minimum phase system in the case of $x_{v}<0$. Under different load pressure differences $p_{L}$, the open-loop transfer function of the power stage system doesn't have positive poles under all working conditions of $x_{v}<0$ (the determination method is the same as that in Fig. 25, due to the limitation of space, Nyquist curve cluster is not shown). Therefore, it can be judged that, in the case of $x_{v}<0$, the power stage system is the minimum phase system and the system is open-loop stable. 


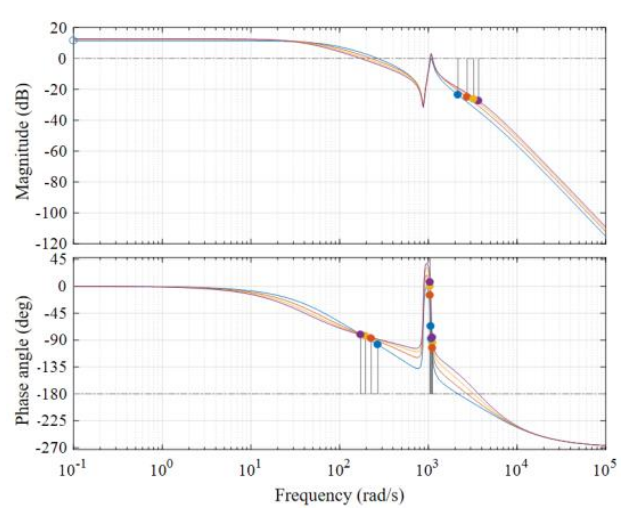

a) $x_{v}=-0.45 \mathrm{~mm}$

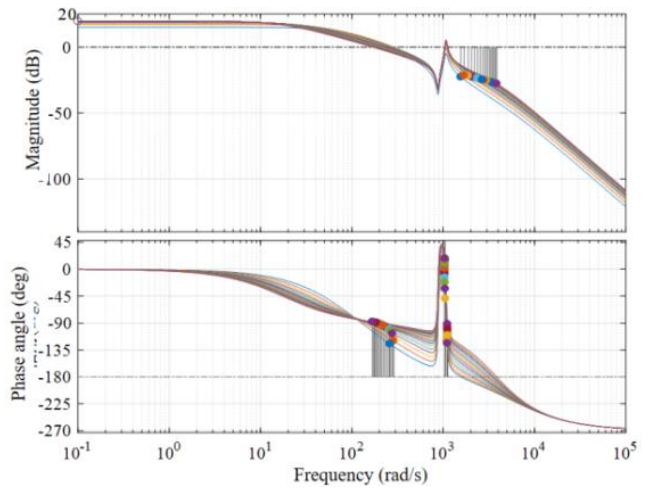

b) $x_{v}=-0.2 \mathrm{~mm}$

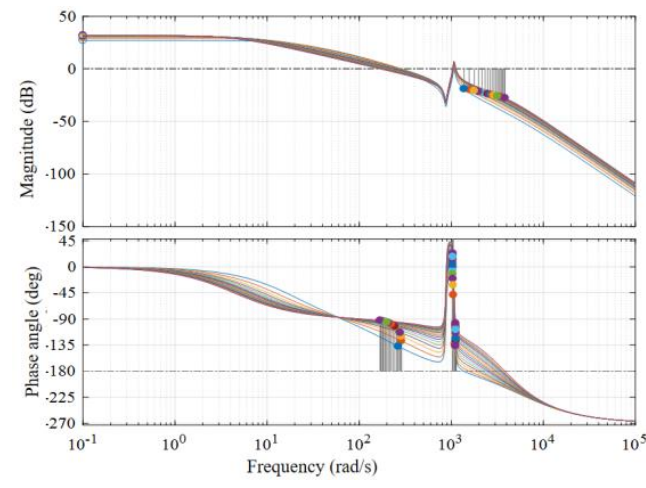

d) $x_{v}=-0.05 \mathrm{~mm}$

Fig. 26. Open-loop Bode diagram with different negative displacement of power valve spool

Under the negative displacement of the spool at different power levels, the real part of the open-loop negative pole point coordinate nearest to the virtual axis of the system is shown in Table 2.

Table 2 The real part of open loop negative pole with different negative power spool displacement
$x_{v}(\mathrm{~mm})$
$-0.45$
$-0.2$
$-0.15$
$-0.1$
$-0.05$

\begin{tabular}{cccccc}
$\begin{array}{c}\text { The real part of } \\
\text { negative pole }\end{array}$ & $-4.96 \mathrm{e}-10$ & $-5.22 \mathrm{e}-10$ & $-5.22 \mathrm{e}-10$ & $-5.33 \mathrm{e}-10$ & $-5.38 \mathrm{e}-10$ \\
\hline
\end{tabular}

It can be seen that the maximum open-loop negative point is close to the virtual axis. When the parameter is disturbed, the open-loop negative point is prone to turn positive, leading to open-loop instability or open-loop critical stability. So there is a potential instability in the system.

According to Fig. 36, the Bode diagram of the power stage system starts from the $0^{\circ}$ line, as positive traversing 0 times. In the frequency range where the open loop logarithmic magnitude frequency characteristic is positive, the open-loop logarithmic phase frequency curve has no other phenomenon of traversing the $-180^{\circ}$ line. Therefore, the difference between the positive and negative traversing times of the $-180^{\circ}$ line of the phase frequency curve is 0 . The stability condition of closed-loop system is satisfied when the system doesn't have an open-loop positive pole. Therefore, in this case of $x_{v}<0$, the system is closed-loop stable.

Since the power stage system is the minimum phase system in the case of $x_{v}<0$, and its stability margin can be determined by the open-loop Bode diagram. Taking 
$p_{L}=6 \mathrm{MPa}$, the open-loop Bode diagram with different negative displacement of power valve spool can be obtained as shown in Fig. 27.

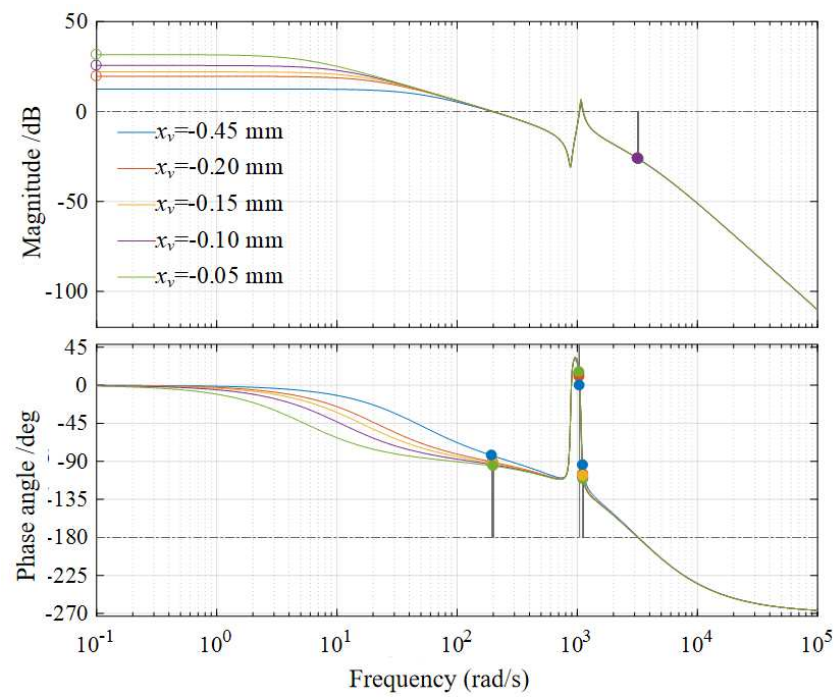

Fig. 27 Open-loop Bode diagram with different negative power valve spool displacement $\left(p_{L}=6 \mathrm{MPa}\right)$

It can be seen that, with the decrease of $x_{v}$, the magnitude of the low frequency band in the open-loop Bode diagram of the system keeps increasing, indicating that the closer to the zero position, the better the effect of instruction tracking, and the smaller the steady-state error. At the same time, the stability margin of the system also decreases slightly with the decrease of the displacement of the power stage valve spool $x_{v}$, which indicates that the stability of the power stage valve spool is poor when it works near zero position.

Combined with the above analysis, it can be concluded that the power stage system is a stable closed-loop control system. However, there are obvious potential unstable factors in the system. When there is parameter disturbance, the system may become instability, which will further worsen the oscillation of the output pressure under the action of the nonlinear link.

Combined with the above analysis, the PSVCS is a stable self-closed loop control system, and has a certain stability margin. At the same time, the closed-loop stability of the system also shows once again that the vibration of the PSVCS is not the divergent vibration and critical constant magnitude oscillation behavior caused by the instability of the linear system, but the self-excited oscillation phenomenon caused by the action of the essential nonlinear link.

\section{Experimental verification}

\subsection{Experimental scheme}

In order to verify the accuracy of the dynamics model of the PSVCS and the analysis results of the nonlinear dynamics behavior of the PSVCS, an experimental platform for load simulation performance testing of the PSVCS (referred to as the experimental platform) is built in this paper. The hydraulic principle of the experimental platform is shown in Fig. 28. 


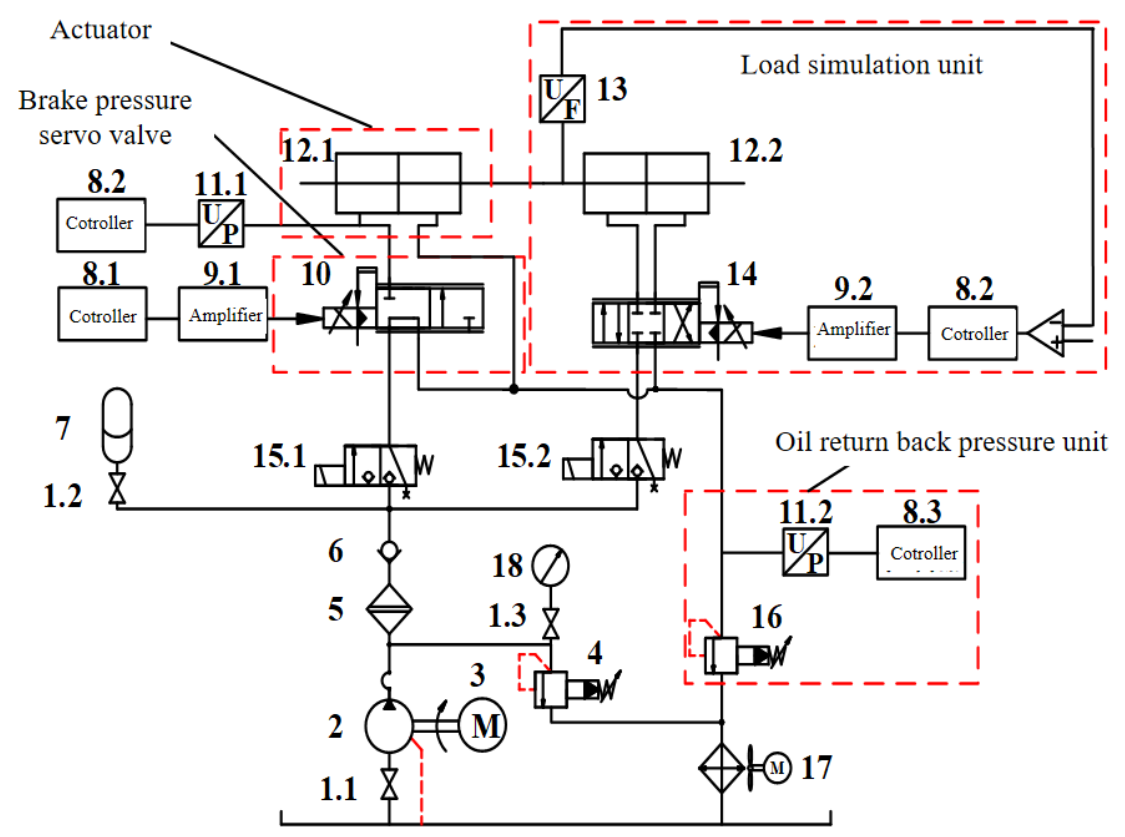

1-Stop valve 2-Quantitative pump 3-Motor 4-Relief valve 5-High pressure filter 6-Check valve 7-Energy accumulator 8-Controller 9-Servo valve amplifier 10-Pressure servo valve 11-Pressure sensor 12-Servo hydraulic cylinder 13-Force sensor 14-Electro-hydraulic servo valve 15-Reversing valve 16-Oil return relief valve 17 -Forced-air cooler

Fig. 28. The hydraulic principle of the experimental platform

Pressure sensor 11.1 is used to measure the working pressure output by the pressure servo valve. The hydraulic cylinder 12.2 on the right, together with the force sensor 13, the servo valve 14 , the controller 8.2 and the amplifier 9.2, jointly constitute the electro-hydraulic load simulator, which performs impedance control in the experiment and is used to simulate the elastic load (load stiffness and load damping) received by the aircraft when braking. The two-position three-way reversing valve 15.1 and 15.2 are respectively used to control the pressure servo valve and the oil circuit of the load simulation unit. Accumulator 7 is used to stabilize the pressure pulsation of hydraulic oil source. Oil return relief valve 16, pressure sensor 11.2 and controller 8.3 constitute the oil return back pressure unit, which is used to set the oil return back pressure of the system. The relief valve 4 and the pressure gauge 18 are used to adjust the outlet pressure of the hydraulic pump. High pressure fine filter 5 is for cleaning oil. Motor 3 drives quantitative pump 2 for system oil supply. Forced-air cooler 17 is used to cool oil.

The basic parameters and the material objects of the experimental platform, such as hydraulic pipeline and load simulation, are shown in Table 3 and Fig. 29 respectively.

Table 3. Basic parameters of the experimental platform

\begin{tabular}{ccccccc}
\hline $\begin{array}{c}\text { Oil supply } \\
\text { pressure }\end{array}$ & System flow & $\begin{array}{c}\text { Brake pipe } \\
(\mathrm{m})\end{array}$ & $\begin{array}{c}\text { Oil return pipe } \\
(\mathrm{m})\end{array}$ & $\begin{array}{c}\text { Oil return } \\
\text { pressure }\end{array}$ & Load stiffness & $\begin{array}{c}\text { Load } \\
\text { damping }\end{array}$ \\
\hline $15 \mathrm{MPa}$ & $6.25 \mathrm{e}-4 \mathrm{~m}^{3} / \mathrm{s}$ & $\phi 0.006 \times 1.50$ & $\phi 0.006 \times 1.01$ & $0.6 \mathrm{MPa}$ & $1000000 \mathrm{~N} / \mathrm{m}$ & $50 \mathrm{~N} \cdot \mathrm{s} / \mathrm{m}$ \\
\hline
\end{tabular}




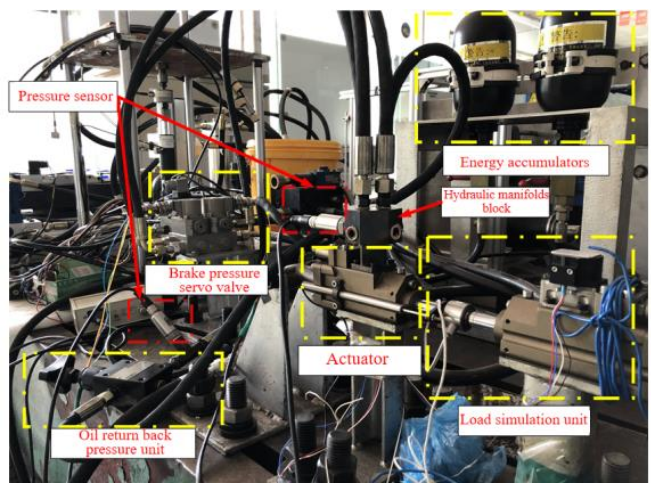

a) Load simulation unit

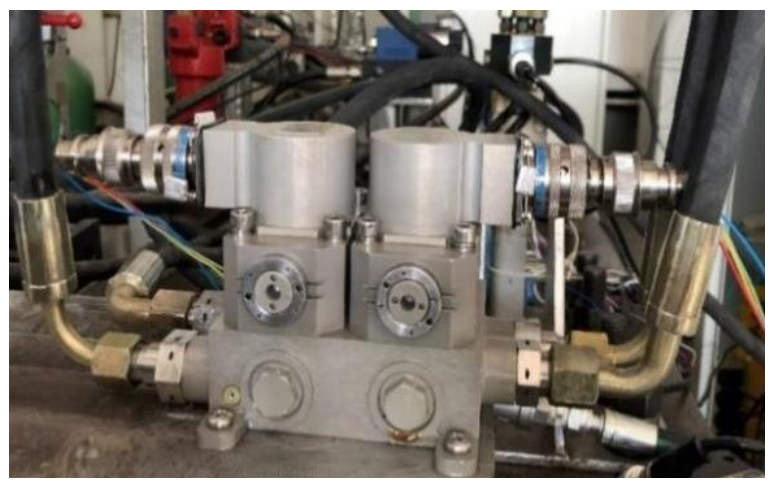

b) Brake pressure servo valve set

Fig. 29 The material objects of the experimental platform

\subsection{Experimental results}

\subsubsection{Step response experiment of PSVCS}

Under the conditions of oil supply pressure $p_{s}=15 \mathrm{MPa}$ and oil return pressure $p_{h}=0.6 \mathrm{MPa}$, the step current signal of $40 \mathrm{~mA}$ is given, and the brake pressure curve measured experimentally is shown in Fig. 30.

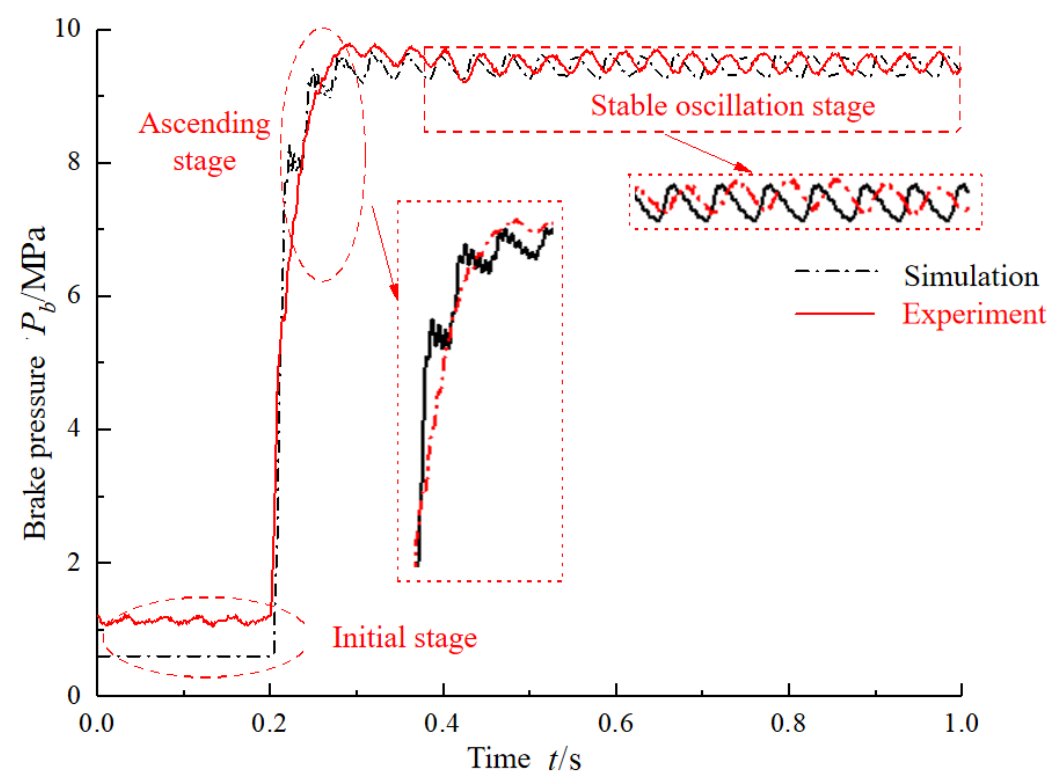

Fig. 30. Experimental results of brake pressure under step signal

According to Fig. 30, the following conclusions can be drawn:

(1) The step response of brake pressure $p_{b}$ can be divided into three stages: initial stage, ascending stage and stable oscillation stage. Among them, the simulation results of the initial stage and the ascending stage are different from the experiment. There is a high similarity between the simulation results and the experimental results in the magnitude and frequency of the stable oscillation.

(2) In the initial stage of zero current, the brake pressure is still a fixed value of $0.6 \mathrm{MPa}$ in the initial stage, while the experimental results show an oscillating waveform, and the average oscillation value is significantly higher than $0.6 \mathrm{MPa}$. The reasons are speculated as follows: in the initial state without input current signal, the displacement of the main valve spool is $x_{v}=-0.5 \mathrm{~mm}$, and the port $\mathrm{B}$ and port $\mathrm{H}$ of brake pressure servo valve are linked. There is a fixed back pressure of $0.6 \mathrm{MPa}$ in the 
oil return channel. Therefore, the initial brake pressure (namely the return oil back pressure) is $0.6 \mathrm{MPa}$. However, in the experiment, the return oil pressure value of 0.6 $\mathrm{MPa}$ is the minimum pressure regulating value of DBD type direct acting relief valve selected, and the pressure stabilizing performance of DBD type direct acting relief valve is poor near this value range. Due to the existence of oil supply pressure, even if the torque motor current signal is zero, there is jet flow in the jet nozzle. However, due to the influence of the brake pressure servo valve structure, all jet flow of the jet nozzle will flow into the oil return channel eventually, and this part of the flow into the oil return cavity will cause the rise of oil return pressure. At the same time, because the oil source of the system is the axial piston pump, its flow pulsation will lead to the flow fluctuation of the jet nozzle, resulting in small fluctuation of the oil return pressure $p_{b}$, namely, the brake pressure in the initial stage.

(3) The simulation results of the stable oscillation stage are relatively similar to the experimental results, both of which are constant magnitude oscillations with a frequency of about $20 \mathrm{~Hz}$ and an magnitude of about $0.4 \mathrm{MPa}$.

Under the condition of frequency range of $0 \sim 100 \mathrm{~Hz}$ and sampling frequency of $60 \mathrm{~Hz}$, FFT analysis is conducted on the data of stable oscillation stage, and the FFT spectrum of stable oscillation stage of brake pressure is obtained, as shown in Fig. 31.

It can be seen from Fig. 31 that the frequencies of the stable oscillation of brake pressure obtained from the simulation analysis and the experimental test are almost completely same, and the magnitude of the oscillation at the main frequency $(25 \mathrm{~Hz})$ is only slightly different. However, the oscillation magnitude of the higher-order component obtained from the simulation analysis is obviously higher than the experimental results, because the simulation model is an ideal model, and the impedance control parameters in the experimental system are difficult to be added accurately. Therefore, the high-order oscillation components eliminated by impedance in the experimental system are still obviously reflected in the simulation analysis. Among them, the most obvious is the response at the third order frequency, which has almost no magnitude in the experiment, indicating that the response of this order is almost completely eliminated by the impedance in the system. At the same time, it can be seen that the oscillation magnitude of the main frequency is much greater than that of the higher-order component, therefore, the vibration energy of the main frequency component has an absolute advantage in the proportion of the total vibration energy, which is reflected in the time domain, namely, the pressure fluctuation with a frequency of about $25 \mathrm{~Hz}$.

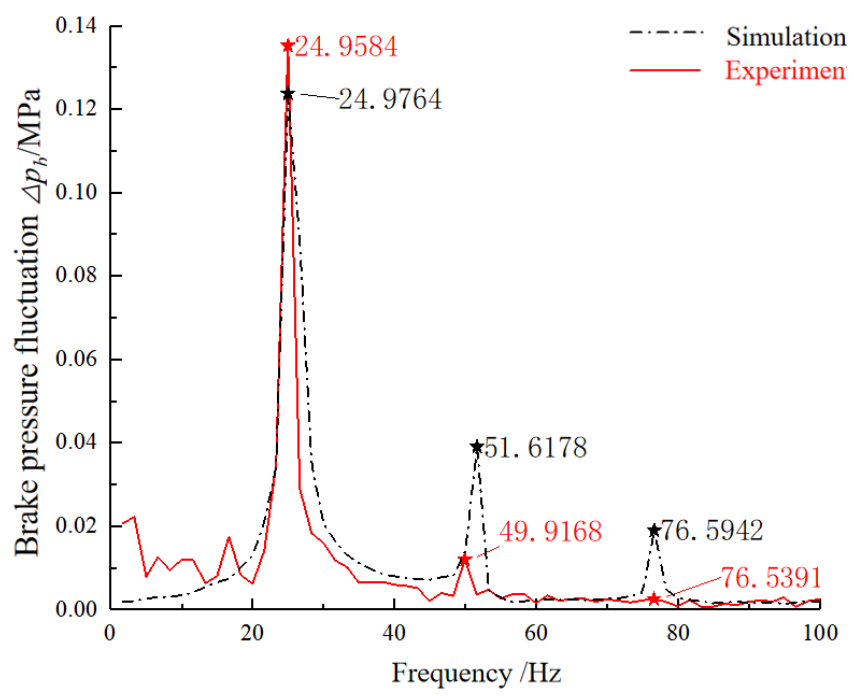


Fig. 31. The FFT spectrum of brake pressure of constant magnitude oscillation stage

The comparison of vibration peak value and main frequency in the stable oscillation stage of brake pressure is shown in Table 4. It can be seen that the system dynamics model can accurately reproduce the constant magnitude oscillation of brake pressure under the step signal.

Table 4. Comparison of brake pressure fluctuation in constant magnitude oscillation stage

\begin{tabular}{ccc}
\hline & Peak-peak value $(\mathrm{MPa})$ & Main frequency $(\mathrm{Hz})$ \\
\hline Experiment & 0.319 & 24.9584 \\
Simulation & 0.347 & 24.9764 \\
Error & $8.8 \%$ & $0.072 \%$ \\
\hline
\end{tabular}

\subsubsection{Experimental study on the effect of oil return cavity on brake pressure servo valve}

By adjusting the length of the oil return hydraulic hose on the experimental platform, the volume of the oil return cavity $V_{h}$ can be approximately adjusted to 1.1 times and 0.9 times of the original volume, namely, the parameter changes are $10 \%$ and $-10 \%$ (too long pipe will make the experimental results greatly affected by the fluid-structure coupling phenomenon), the oil return hydraulic hose used is shown in Fig. 32.

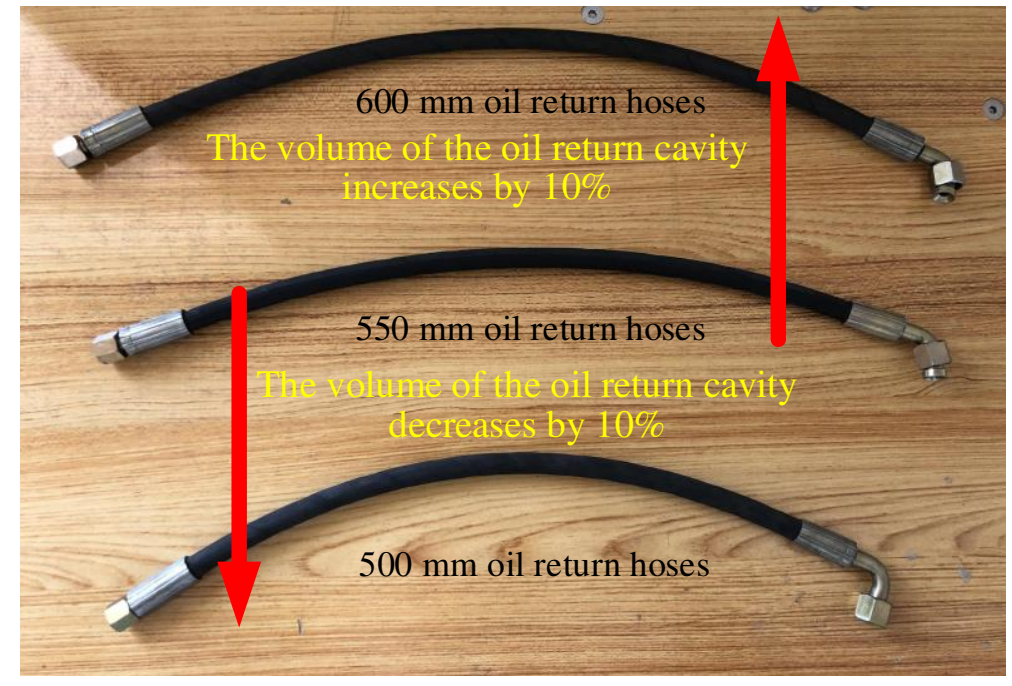

Fig. 32. The hydraulic hoses with different length

Under the conditions of oil supply pressure $p_{s}=15 \mathrm{MPa}$ and oil return pressure $p_{h}=0.6 \mathrm{MPa}$, the brake pressure servo valve is input $40 \mathrm{~mA}$ step current signal. The output pressure curves of the brake pressure servo valve under different oil return cavities are measured respectively.

The experimental scheme is shown in Table 5.

Table 5. The experimental scheme

\begin{tabular}{cccccc}
\hline $\begin{array}{c}\text { Serial } \\
\text { number }\end{array}$ & $\begin{array}{c}\text { Length of the oil } \\
\text { return hose }(\mathrm{mm})\end{array}$ & Changes of $V_{h}$ & $\begin{array}{r}\text { Oil supply } \\
\text { pressure } p_{s}\end{array}$ & $\begin{array}{r}\text { Oil return } \\
\text { pressure } p_{h}\end{array}$ & $\begin{array}{c}\text { Step current } \\
\text { signal }\end{array}$ \\
\hline 1 & 550 & No change & & $p_{h}=0.6 \mathrm{MPa}$ & $40 \mathrm{~mA}$ \\
2 & 600 & Increase 10\% & $15 \mathrm{MPa}$ & & \\
3 & 500 & Decrease 10\% & & & \\
\hline
\end{tabular}


The output pressure curve of the brake pressure servo valve is shown in Fig. 33.

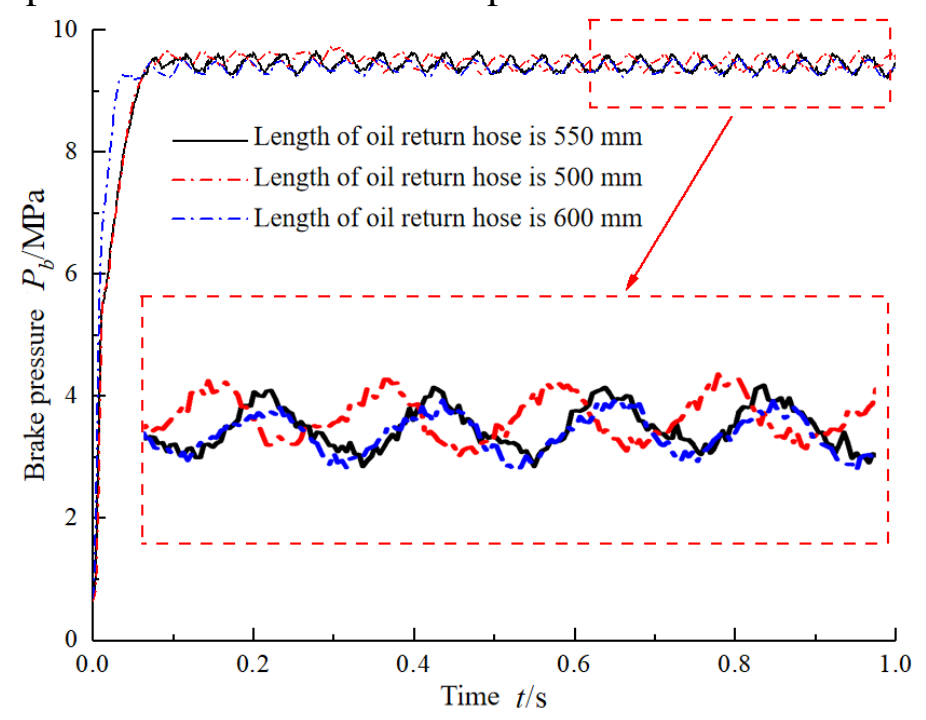

Fig. 33. Braking pressure curves corresponding to hydraulic return hose of different lengths

It can be seen from Fig. 33 that the brake pressure obtained from the experiment has obvious constant magnitude oscillation phenomenon with the oil return hoses of different lengths, but the oscillation peak value is significantly smaller than that obtained from the simulation analysis. This is because the model obtained in Section 2 of this paper is used in the dimensionless analysis. The model linearizes the flow rate of the jet nozzle, and the oil return pressure $p_{h}$ has little effect on the buildup pressure $p_{c}$, which is equivalent to weakening the inhibition effect of the feedback stage on the oil return positive feedback. Therefore, the magnitude of brake pressure oscillation obtained by the simplified model is larger than that obtained by the original model.

Meanwhile, it can be seen from Fig. 33 that the peak value of brake pressure oscillation decreases with the return pipe length increased. For further comparative analysis, peak values of the stable oscillation segments of each curve in Fig. 33 are averaged, and the obtained results are shown in Table 6.

Table 6 The peak value of brake pressure oscillation corresponding to oil return hoses

\begin{tabular}{cccc}
\hline Length of oil return hose (mm) & 500 & 550 & 600 \\
\hline Peak-peak value (MPa) & 0.331 & 0.326 & 0.319 \\
\hline
\end{tabular}

Taking the oil return hose length of $550 \mathrm{~mm}$ as the standard, the change percentage of brake pressure oscillation peak values can be obtained with the oil return cavity increased by $10 \%$ and decreased by $10 \%$, namely:

$$
\begin{gathered}
\xi_{+10 \% \text { Experiment }}=\frac{0.319-0.326}{0.326} \%=-2.15 \% \\
\xi_{-10 \% \text { Experiment }}=\frac{0.331-0.326}{0.326} \%=1.53 \%
\end{gathered}
$$

In the simulation analysis, the change percentage of brake pressure oscillation peak valve is as follows with the oil return capacity cavity increased by $10 \%$ or decreased by $10 \%$.

$$
\xi_{+10 \% \text { Simulation }}=\frac{13.27-13.45}{13.45} \%=-1.3 \%
$$




$$
\xi_{-10 \% \text { Simulation }}=\frac{13.69-13.45}{13.45} \%=1.78 \%
$$

It can be seen that the simulation analysis has a good accuracy in predicting the influence trend of the change of oil return cavity on the change of brake pressure.

At the same time, the experimental data of brake pressure when the length of the return hose changes are processed by FFT. When the sampling frequency is $60 \mathrm{~Hz}$ and the frequency range is $0 \sim 100 \mathrm{~Hz}$, the obtained FFT spectrum of brake pressure is shown in Fig. 34.

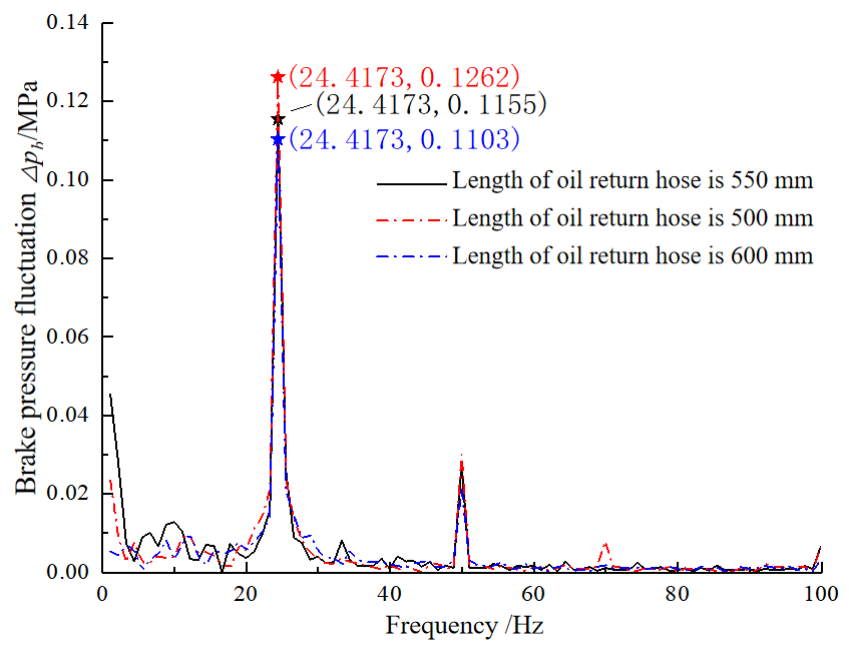

Fig. 34. The experimental FFT spectrum of brake pressure with different hydraulic hoses

As can be seen from Fig. 34, when the oil return hoses of different lengths are used, the main frequency of brake pressure fluctuation doesn't change, and only the response peak value corresponding to the main frequency has a slight change. This is somewhat different from the conclusion obtained in above analysis that "the increase of oil return cavity will cause a slight increase in the main frequency of brake pressure oscillation". This is because the oil return hydraulic hoses of different lengths are replaced in the experiment to approximate the change of oil return chamber volume. However, in practice, the oil return cavity volume includes not only the pipeline but also the valve content cavity of the oil return relief valve and the brake pressure servo valve. As a result, the change of oil return cavity volume in the experiment is less than that in the simulation analysis, resulting in a slight difference between the experimental results and the simulation analysis.

\section{Conclusion}

In this paper, based on the nonlinear mathematical model of PSVCS, a two-dimensional phase plane of the power stage valve spool of the brake pressure servo valve is drawn by phase plane analysis, which is composed of displacement and velocity, the influence law of the volume of the oil return cavity on the nonlinear dynamic behavior of the PSVCS is analyzed. On this basis, the stability of the prestage and the power stage of the PSVCS is analyzed respectively. Finally, the stability margin of the whole braking system is obtained, and the following conclusions are obtained through theoretical analysis and experimental verification.

1) Under the signal of $40 \mathrm{~mA}$ step current, the PSVCS has a stable limit-cycle. The movement of the system at the equilibrium point is a stable self-excited oscillation. With the different motion states of the valve spool at the power stage, the brake pressure fluctuates up and down within a certain range.

2) With the increase or decrease of the control parameter (the volume of the oil 
return cavity $V_{h}$ ), the peak value of the constant magnitude oscillation formed by the brake pressure decreases or increases obviously. The volume of the oil return cavity $V_{h}$ is inversely proportional to the magnitude of the self-excited vibration of the brake pressure, which means the increasing of $V_{h}$ can decrease the magnitude of vibration. However, the volume of oil return cavity $V_{h}$ has little effect on the main frequency of self-excited vibration.

3) The prestage of the brake pressure servo valve is stable and has a large gain margin $(12.1 \mathrm{~dB}>6 \mathrm{~dB})$ and phase margin $(84.3 \mathrm{deg}>30 \mathrm{deg})$, which can remain stable under certain external disturbances, and the power stage is a stable closed-loop control system. However, the power stage has obvious potential instability factors. When the parameter is disturbed, the system may become unstable, which further aggravates the system output pressure and leads to the self-excited oscillation under the action of nonlinear link.

\section{Data Availability Statement}

The data used to support the findings of this study will be made available from the corresponding author on reasonable request..

\section{Conflicts of Interest}

The authors declare that they have no conflicts of interest.

\section{Funding Statement}

This work was supported by National Key R\&D Program of China (Grant No 2018YFB2000701) and National Natural Science Foundation of China (Grant No. 51905465).

\section{Reference}

[1] Wang X Z, Wan W Z, Liu Z, et al. Integrated optimization on aerodynamics-structure coupling and flight stability of a large airplane in preliminary design[J]. Chinese Journal of Aeronautics, 2018, 31(6):1258-1272.

[2] Dickinson, H B. Mauverability and Control Surface Strength Criteria for Large Airplanes[J]. Journal of the Aeronautical Sciences, 2015, 7(11):469-477.

[3] Viscardi M, Arena M, Cerreta P, et al. Manufacturing and Validation of a Novel Composite Component for Aircraft Main Landing Gear Bay[C]. International Symposium on Dynamic Response and Failure of Composite Materials (Draf), 2019.

[4] Viscardi M, Arena M, Cerreta P, et al. Design and prototyping of a novel composite architecture for a widebody landing gear bay[J]. Materials Today, 2021, 34(1):288-292.

[5] Grinis L, Haslavsky V, Tzadka U. Self-Excited Vibration in Hydraulic Ball Check Valve[J]. World Academy of Science Engineering \& Technology, 2012, 51(1):311-314.

[6] Han H, Jeon S, Lee C, et al. Self-excited vibration of an impeller blade of the waterjet propulsion shaft in a naval vessel caused by flow-induced thrust load[J]. Engineering Failure Analysis, 2020, 118:104888. 
[7] Wei D G, Zhai W H, Zhu Y J, et al. Self-excited vibration of whole vehicle with multiple limit-cycles induced by shimmy of front wheels[J]. Journal of Low Frequency Noise Vibration and Active Control, 2020, 39(4):1052-1064.

[8] Li Y W, Jiao Z X, Xu Y Z. Nonlinear Analysis of Oscillations in Aero-hydraulic Actuation System Considering Load Effect[C]. International Conference on Fluid Power and Mechatronics, 2015.

[9] Motallebia A, Doniavi A, Sahebi Y. An Analysis and Modeling of the Dynamic Stability of the Cutting Process Against Self-Excited Vibration[J]. Mechanics and Mechanical Engineering, 2020, 22(4):1287-1300.

[10] Khankalantary S, Izadi I, Sheikholeslam F. Robust ADP-based solution of a class of nonlinear multi-agent systems with input saturation and collision avoidance constraints[J]. ISA Transactions, 2020, 107:52-62.

[11] A M A, A M M M, B H N. A novel zero delay low pass filter: Application to precision positioning systems[J]. ISA Transactions, 2021, Doi:10.1016/j.isatra.2020.11.013.

[12] Karuna K, Sukanta D. Implementation of reactive power-based MRAS for sensorless speed control of brushless doubly fed reluctance motor drive[J]. Iet Power Electronics, 2018, 11(1):192-201.

[13] Oleg C, Alena Z, Nina S. Optimal Thrust Programming Along the Brachistochronic Trajectory with Non-linear Drag[J]. International Journal of Nonlinear Sciences and Numerical Simulation, 2019, 20(1):63-68.

[14] Ronilson R, Rene O M. Stability analysis for the Chua circuit with cubic polynomial nonlinearity based on root locus technique and describing function method[J]. Nonlinear Dynamics, 2020, 102(4):2859-2874.

[15] Islam M M, Siffat S A, Ahmad I, et al. Robust integral backstepping and terminal synergetic control of course keeping for ships[J]. Ocean Engineering, 2021, 221(1):108532.

[16] Zare A, Mirrezapour S Z, Hallaji M, et al. Robust Adaptive Synchronization of a Class of Uncertain Chaotic Systems with Unknown Time-Delay[J]. Applied Sciences-Basel, 2020, 10(24):8875.

[17] Zhang S Z, Li S Z. Cavity shedding dynamics in a flapper-nozzle pilot stage of an electro-hydraulic servo-valve: Experiments and numerical study[J]. Energy Conversion and Management, 2015, 100:370-379.

[18] Glaun A. Avoiding Flow-Induced SyMPathetic Vibration in Control Valves [J]. Power, 2012, 156(2): 80-83.

[19] Liu J X, Qiao B J, Zhang X W, et al. Adaptive vibration control on electrohydraulic shaking table system with an expanded frequency range: Theory analysis and experimental study[J]. Mechanical Systems and Signal Processing, 2019, 132:122-137.

[20] Wang H, Gong G F, Zhou H B, et al. A rotary valve controlled electro-hydraulic vibration exciter[J]. Proceedings of The Institution of Mechanical Engineers Part C-Journal of Mechanical Engineering, 2016, 230(19):3397-3407.

[21] Liu Y, Wang T, Gong G F, et al. Present Status and Prospect of High-Frequency Electro-hydraulic Vibration Control Technology[J]. Chinese Journal of Mechanical Engineering, 2019, 32(1):93. 